\title{
庭院住宅为了健康和幸福 Courtyard Housing for Health and Happiness
}

\author{
张晓东 博士 \\ Donia Zhang, PhD
}

国际智慧城市与绿色发展专题研讨会 - 智慧城市创新圆桌会 2017 Innovation Summit on Smart City and Green Development Innovation Round Table for Smart City

Beijing, China, July 7, 2017 


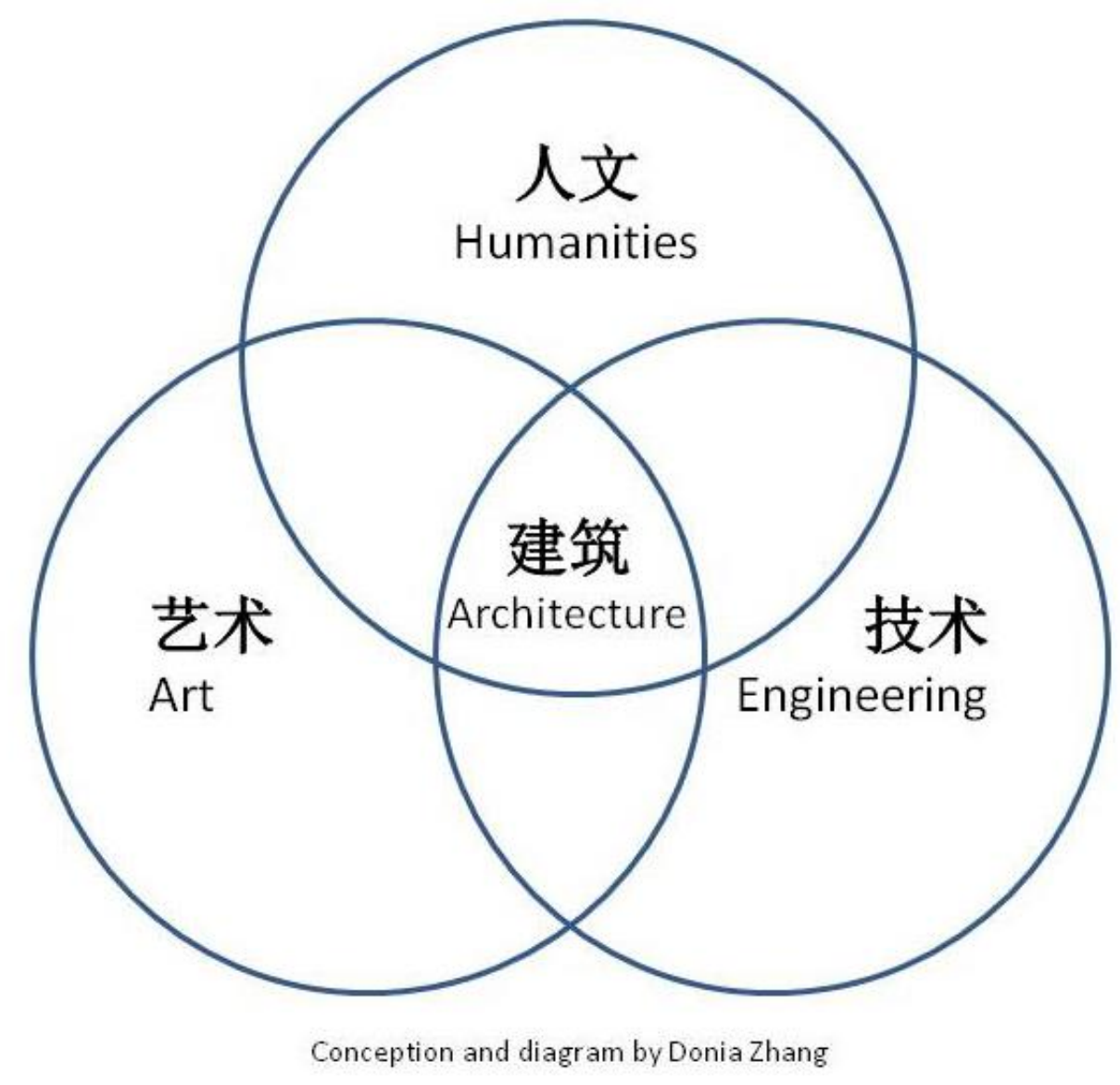

建筑是技术，艺术，与人文的结合 Architecture is the integration of engineering, art, and humanities 


\section{介绍 \\ Introduction}

(. This presentation examines courtyard housing projects built in

China (Beijing and Suzhou) since the 1990s, and in North America (USA and Canada) since the 1910s

(1) It highlights my 2007 (China) and 2013 (North America) empirical research findings on the relationship of housing, health, happiness, harmony, and cultural sustainability

(-) It finally proposes four courtyard garden house schemes that may have universal implications 


\section{可持续发展的四大支柱 \\ Four Pillars of Sustainable Development}

๑ Environmental responsibility 环境责任

๑. Economic viability 经济繁荣

( · Social equity 社会平等

๑ C Cultural vitality 文化活跃

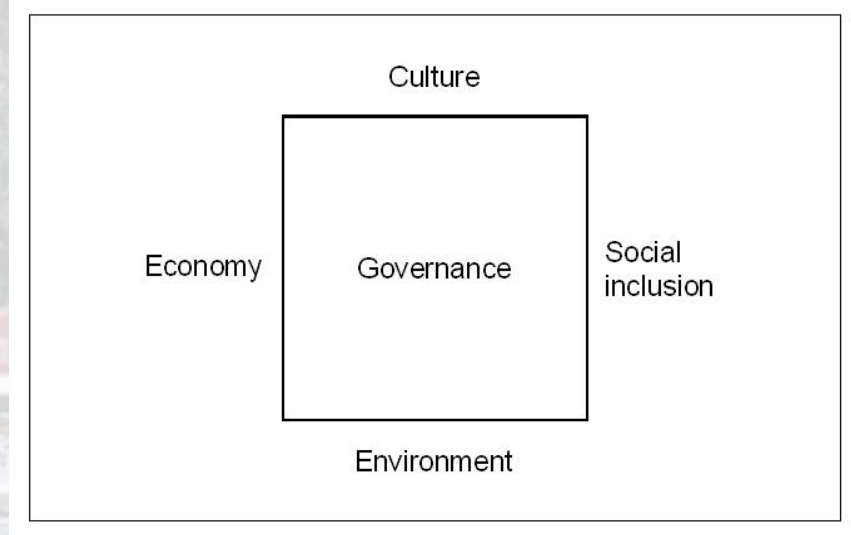




\section{Courtyard Housing in China \\ Four Key Themes in Chinese Philosophy}

(. Harmony with Heaven - form and environmental quality

(. Harmony with Earth - space and construction quality

๑) Harmony with Humans - matters of social cohesion

๑ Harmony with Self - time and cultural activities

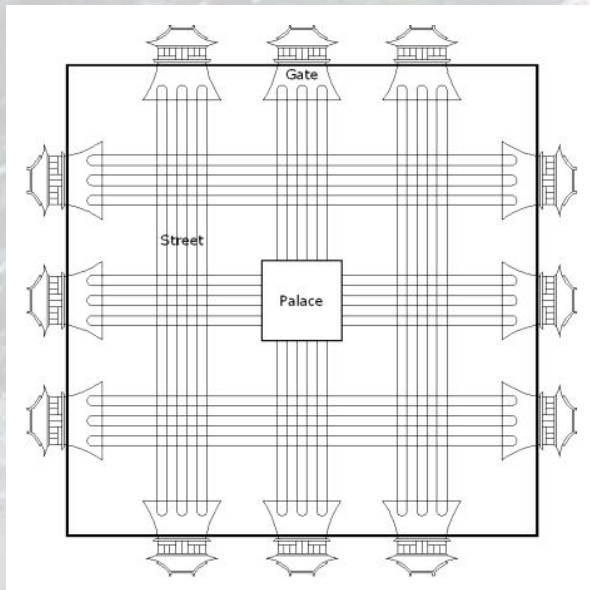

The ideal capital city in imperial China from the Record of Trades in Rituals of Zhou (c.1066-221 BCE). All the measurements within it are multiples of heavenly number 3 . Source: after Liu, 2002

\begin{tabular}{|c|c|c|}
\hline $\begin{array}{c}\text { 私 } \\
\text { Private }\end{array}$ & $\begin{array}{c}\text { 私 } \\
\text { Private }\end{array}$ & $\begin{array}{c}\text { 私 } \\
\text { Private }\end{array}$ \\
\hline $\begin{array}{c}\text { 私 } \\
\text { Private }\end{array}$ & $\begin{array}{c}\text { 公 } \\
\text { Public }\end{array}$ & $\begin{array}{c}\text { 私 } \\
\text { Private }\end{array}$ \\
\hline $\begin{array}{c}\text { 私 } \\
\text { Private }\end{array}$ & $\begin{array}{c}\text { 私 } \\
\text { Private }\end{array}$ & $\begin{array}{c}\text { 私 } \\
\text { Private }\end{array}$ \\
\hline
\end{tabular}

The Nine Squares System (井田制). Source: after the Complete Chinese Dictionary, 1915; Chinese-English Dictionary, 1980

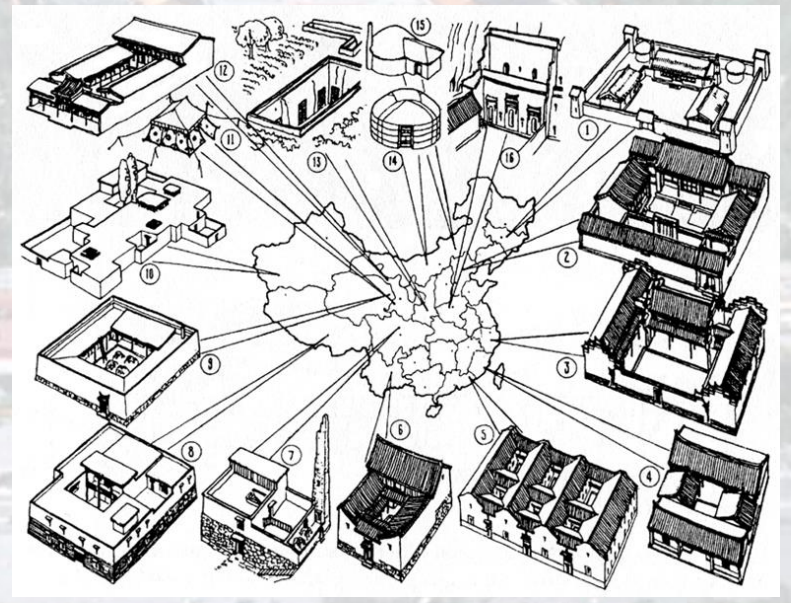

House types across China showing the courtyard as a common feature. Source: Drawing by Fu Xinian in Liu, 1990, p. 206 


\section{Beijing's City Planning}
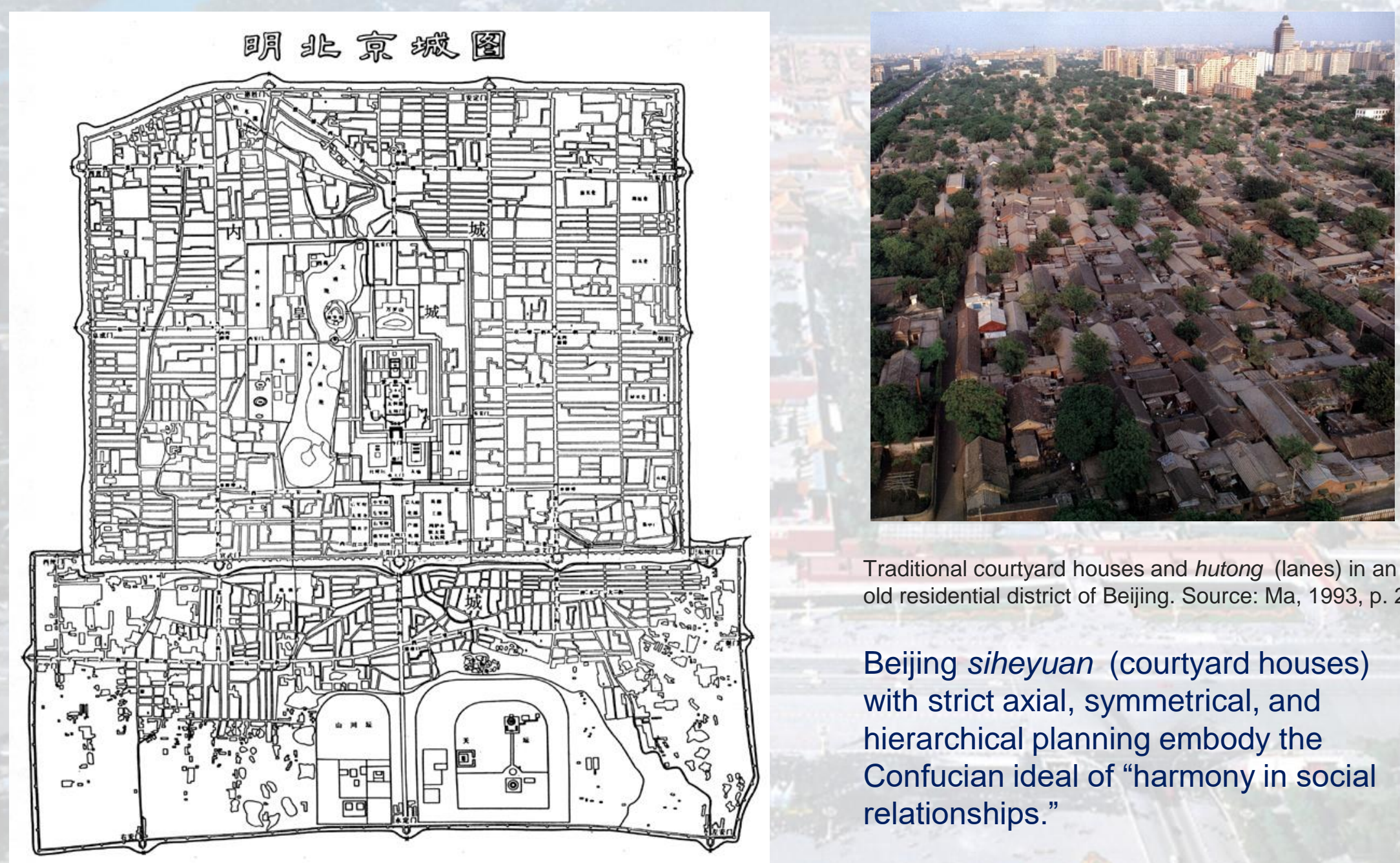

Traditional courtyard houses and hutong (lanes) in an old residential district of Beijing. Source: Ma, 1993, p. 2

Beijing siheyuan (courtyard houses) with strict axial, symmetrical, and hierarchical planning embody the Confucian ideal of "harmony in social relationships." 


\section{Traditional Courtyard Houses of Beijing}

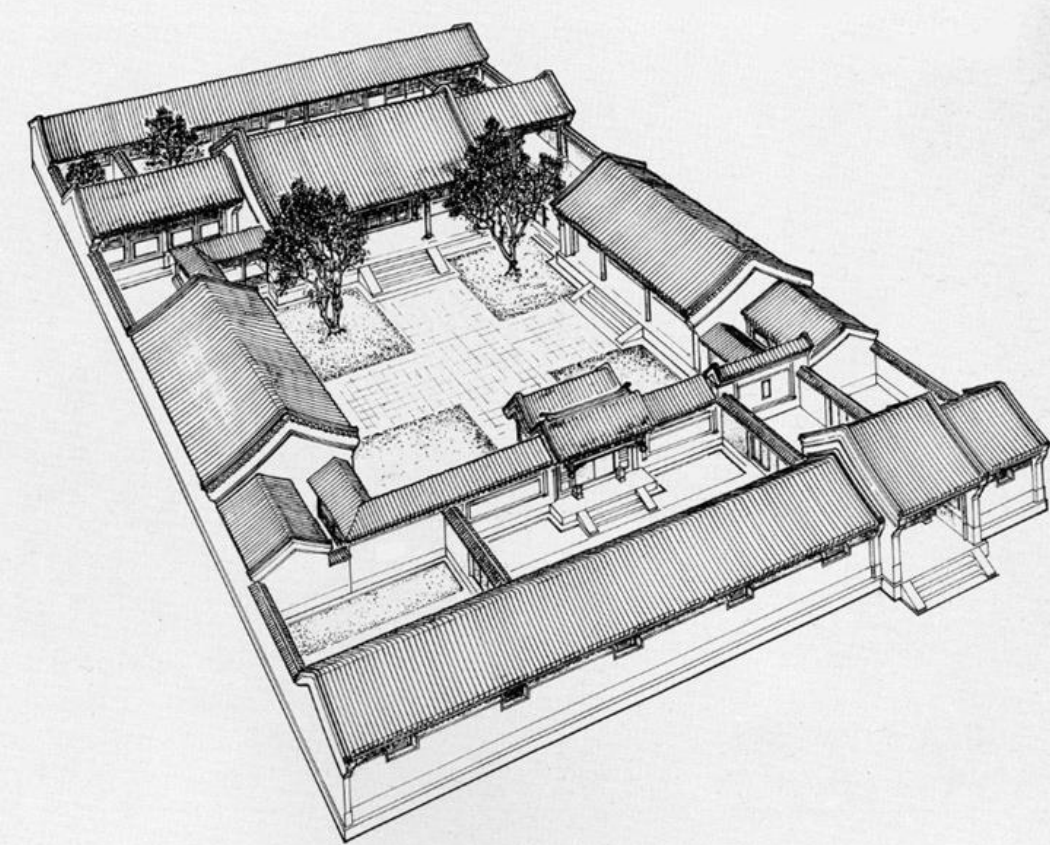

A typical or standard three-courtyard house of Beijing. Source: Ma, 1999, p. 7

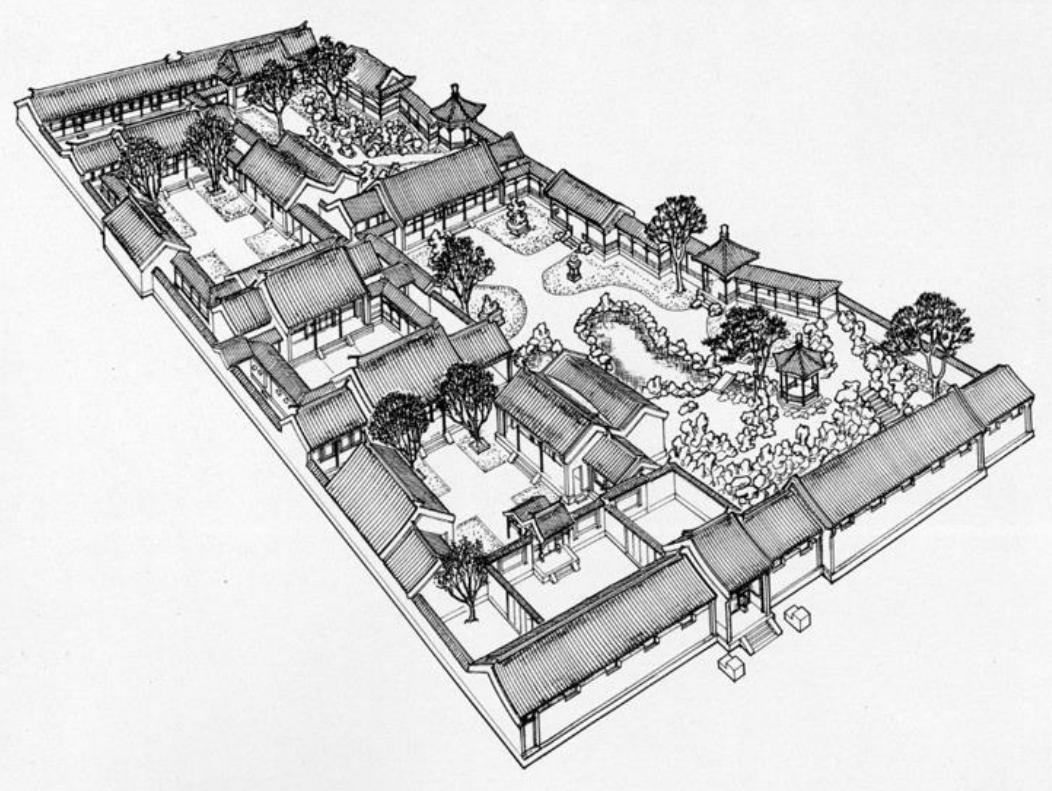

A large, five-courtyard house with gardens in Beijing. Source: Ma, 1999, p. 227 


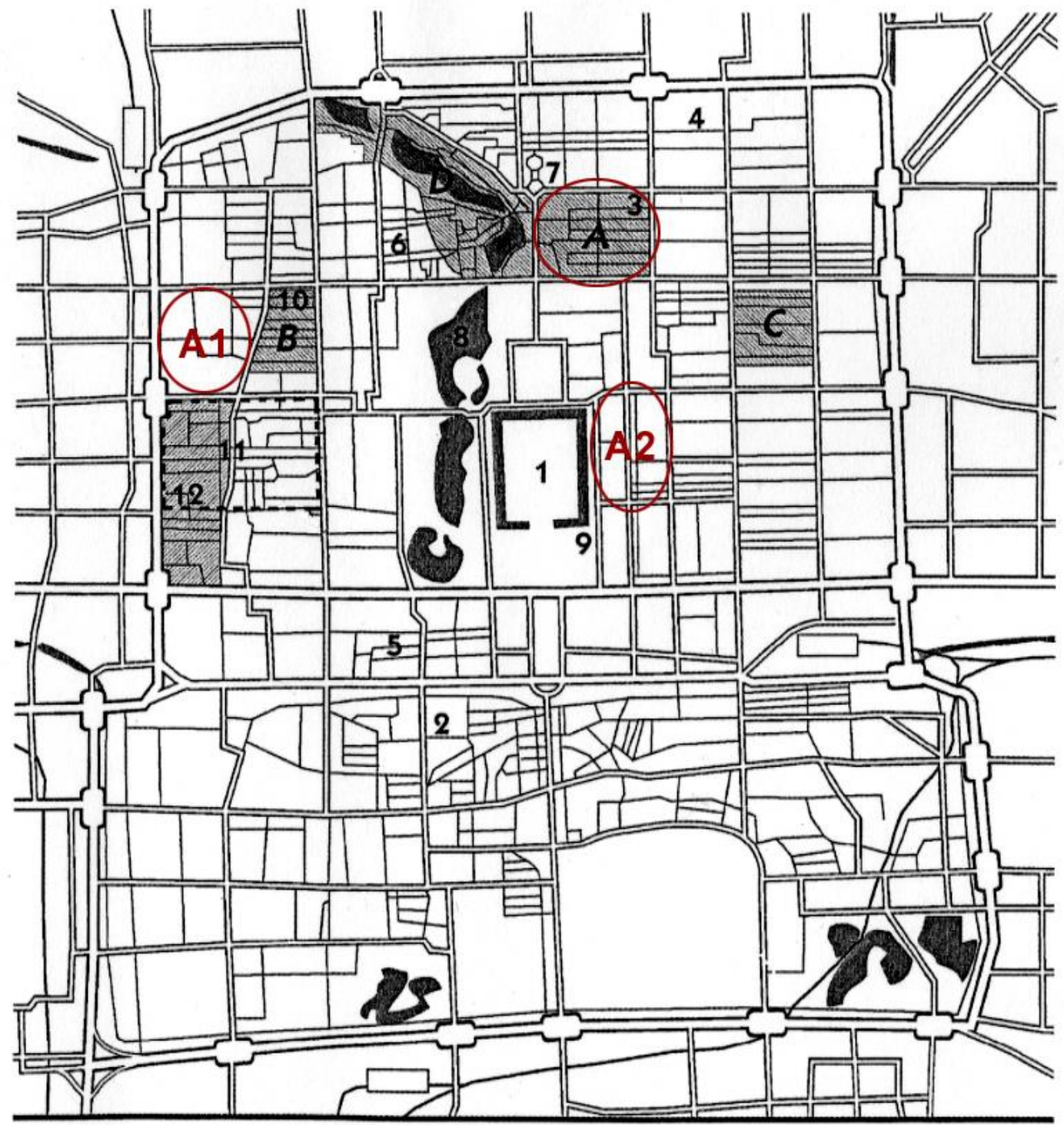

0 $1 \mathrm{~km}$ ते
Classic Sihevuan Preservation Districts and Shichahai Preservation District. $\begin{array}{llll}A & \text { Nan Luogu Xiang } B \text { Xisi Bei } & C \text { Dongsi } & D\end{array}$

1. Forbidden City

4. Guo Zi Jian

2. Liu Li Chang

7. Drum and Bell Towers

10. Xisi Bei \#6-8 Hutongs

12. Financial Street
5. Rong Bao Zhai

8. Beihai [11] feng Sheng Subdistrict
3. Ju er Hutong

6. Mei Lanfang house

9. Nanchizl
Location map of the three Beijing cases. Source: adapted from Abramson, 2001 


\section{Renewed and New Courtyard Housing built in Beijing since the 1990s}

\section{All Photos by Donia Zhang 2007}

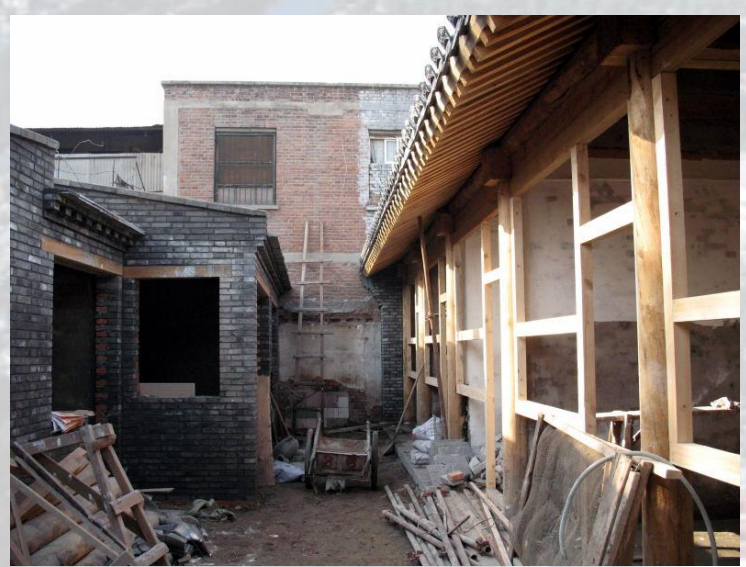

Traditional courtyard house renewal

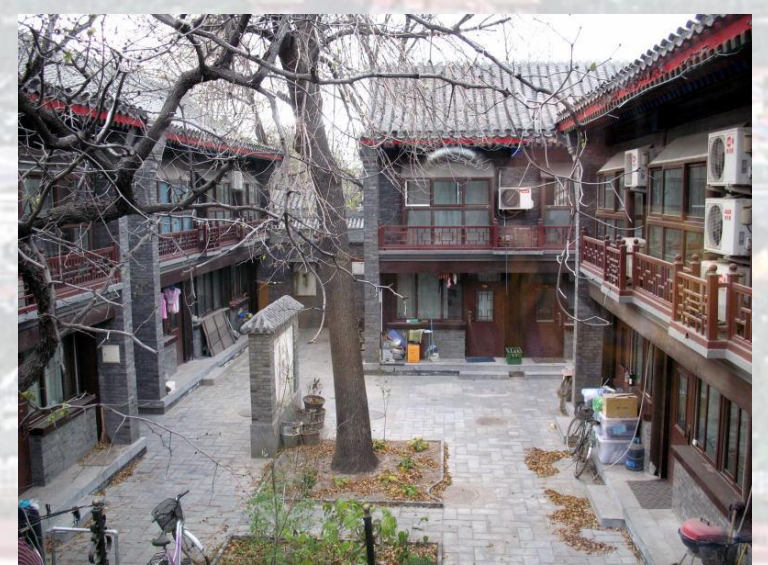

Nanchizi New Courtyard Housing

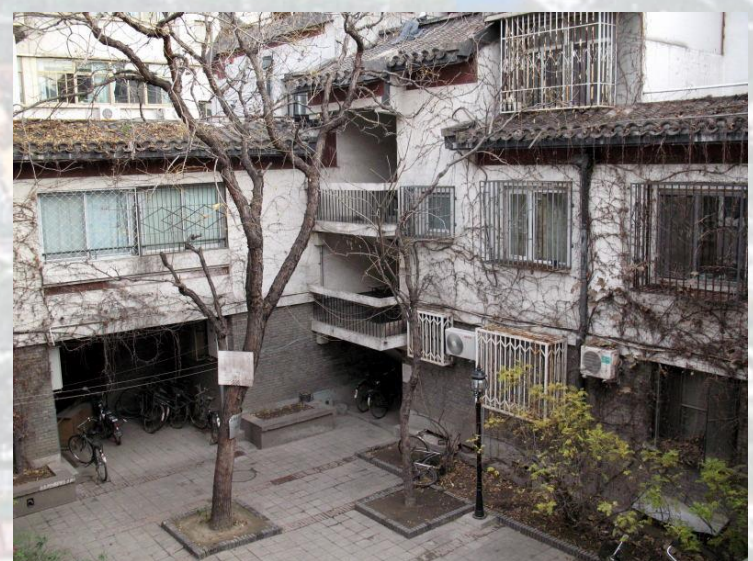

Juer Hutong New Courtyard Housing 


\section{Renewed Traditional Courtyard Houses}
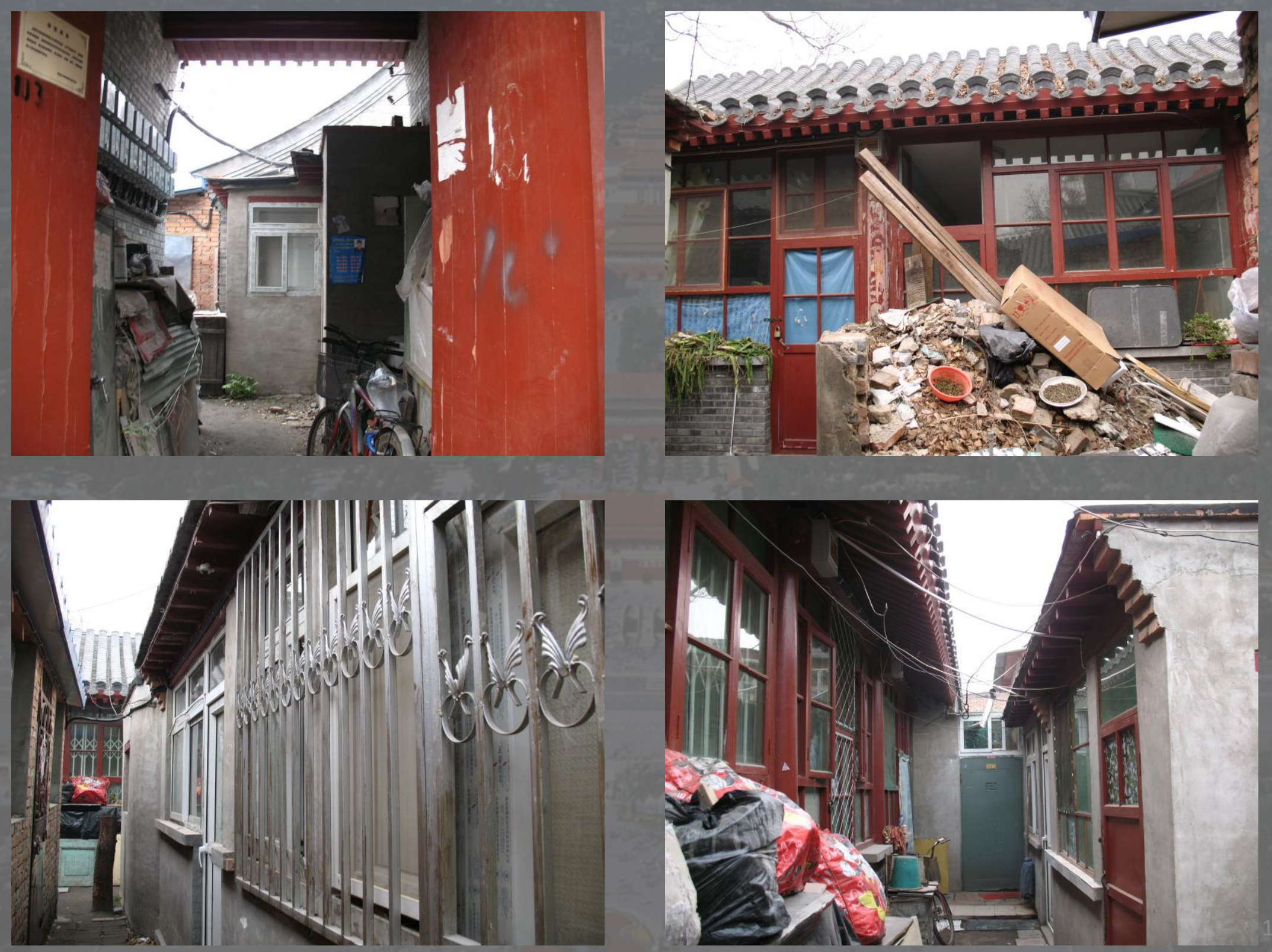
Renewed Traditional Courtyard Houses
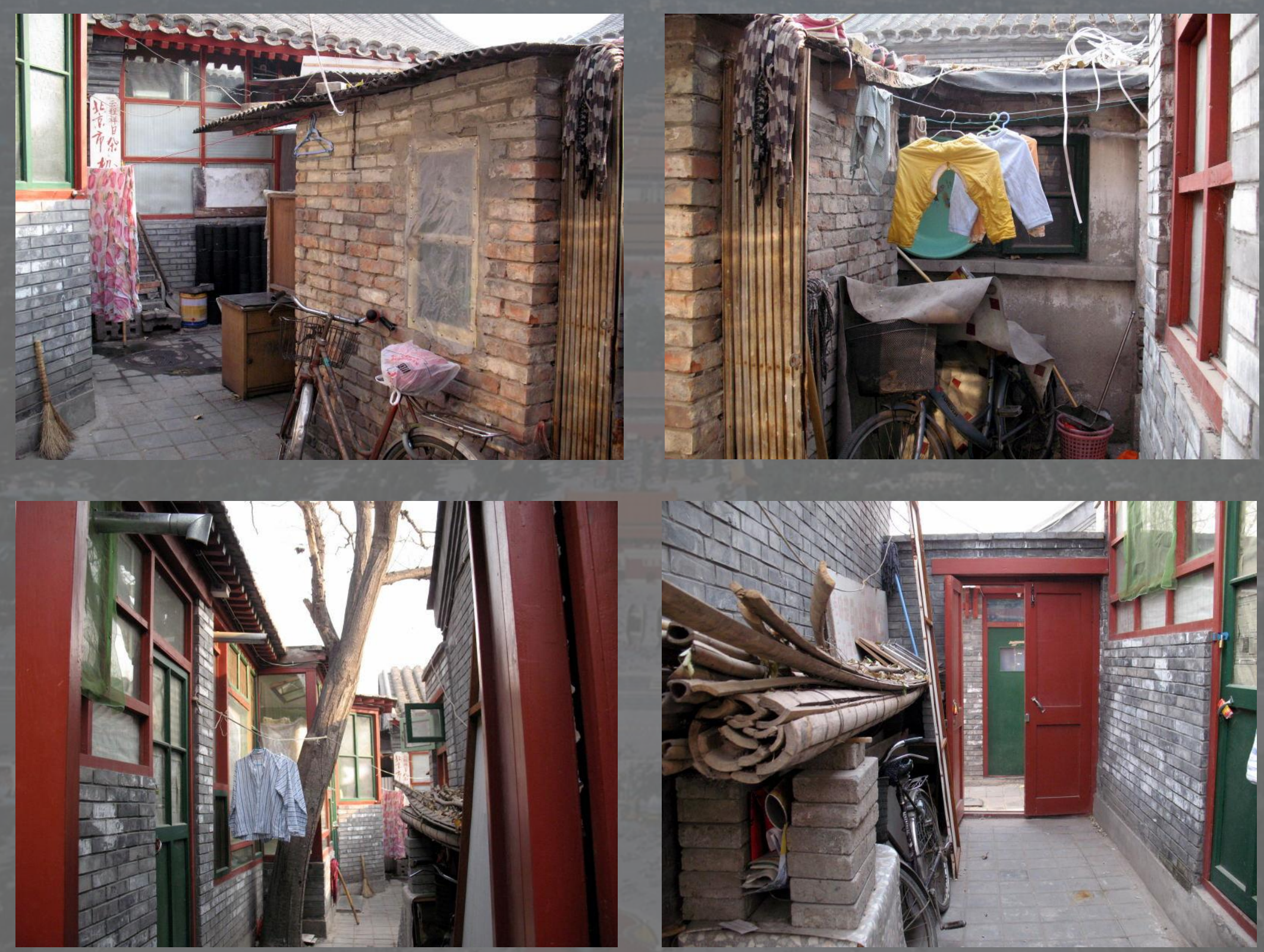


\section{Renewed Traditional Courtyard Houses}
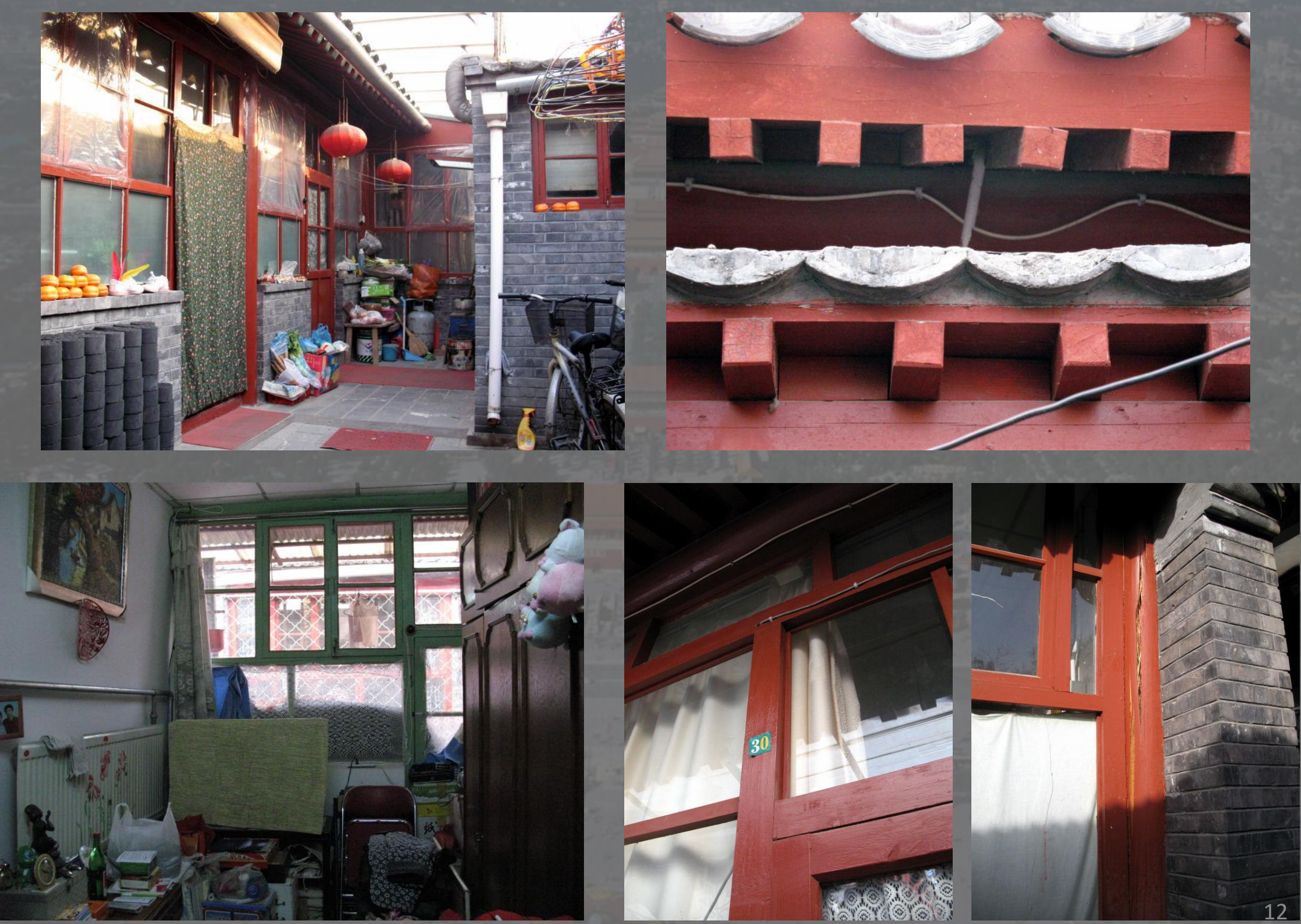
Renewed Traditional Courtyard Houses

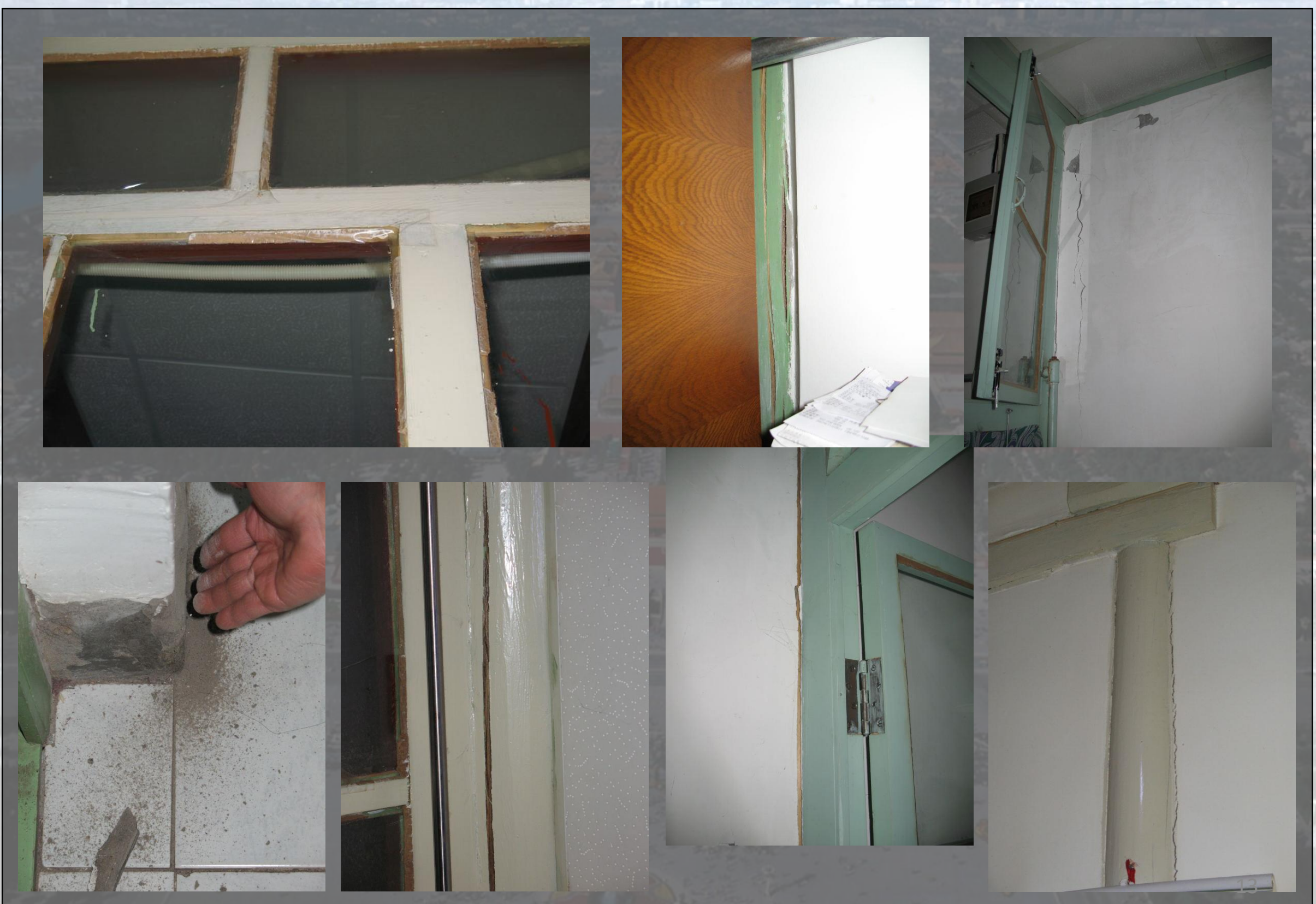




\section{Nanchizi New Courtyard Housing}
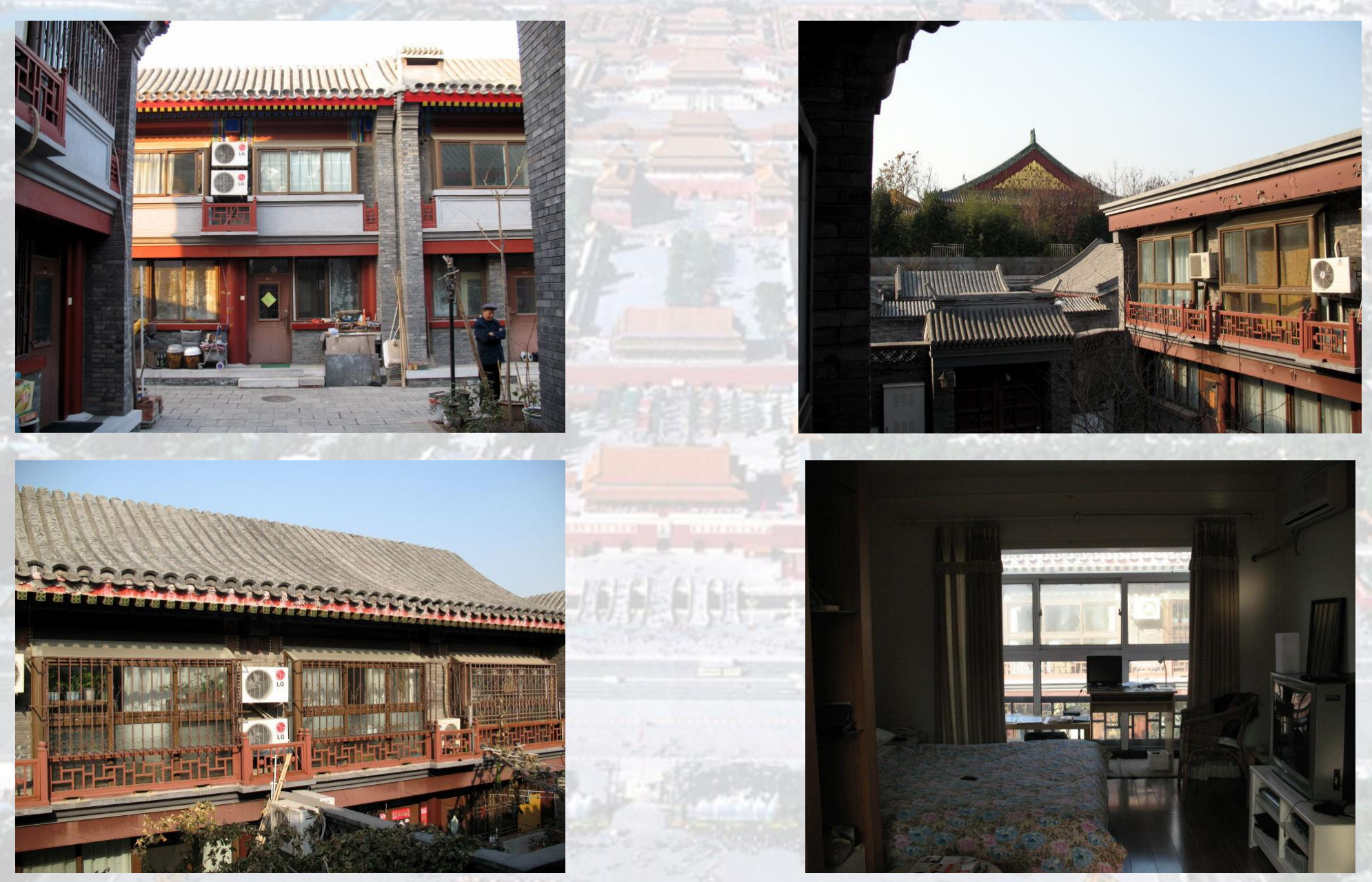


\section{Nanchizi New Courtyard Housing}
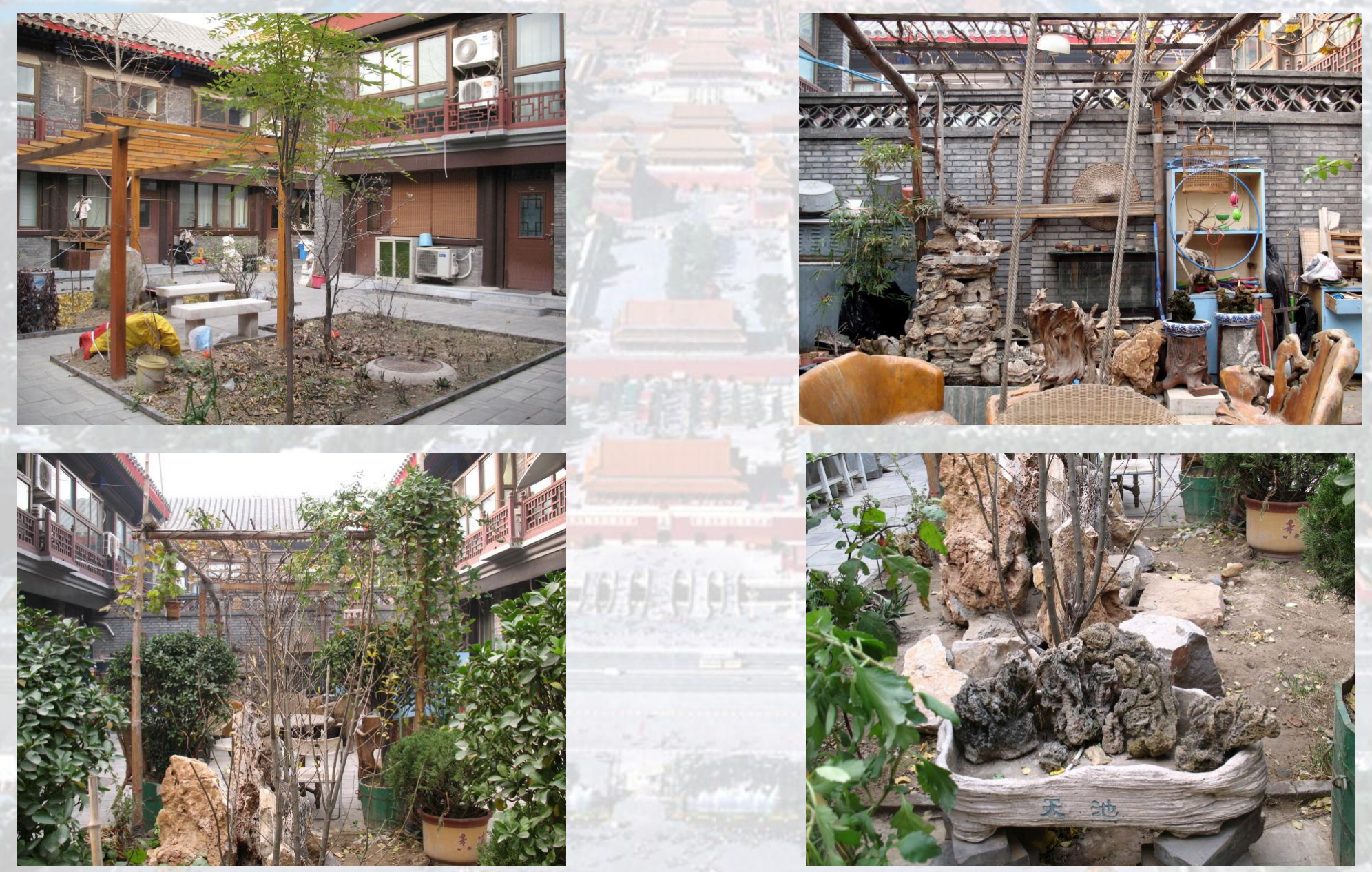


\section{Juer Hutong New Courtyard Housing}

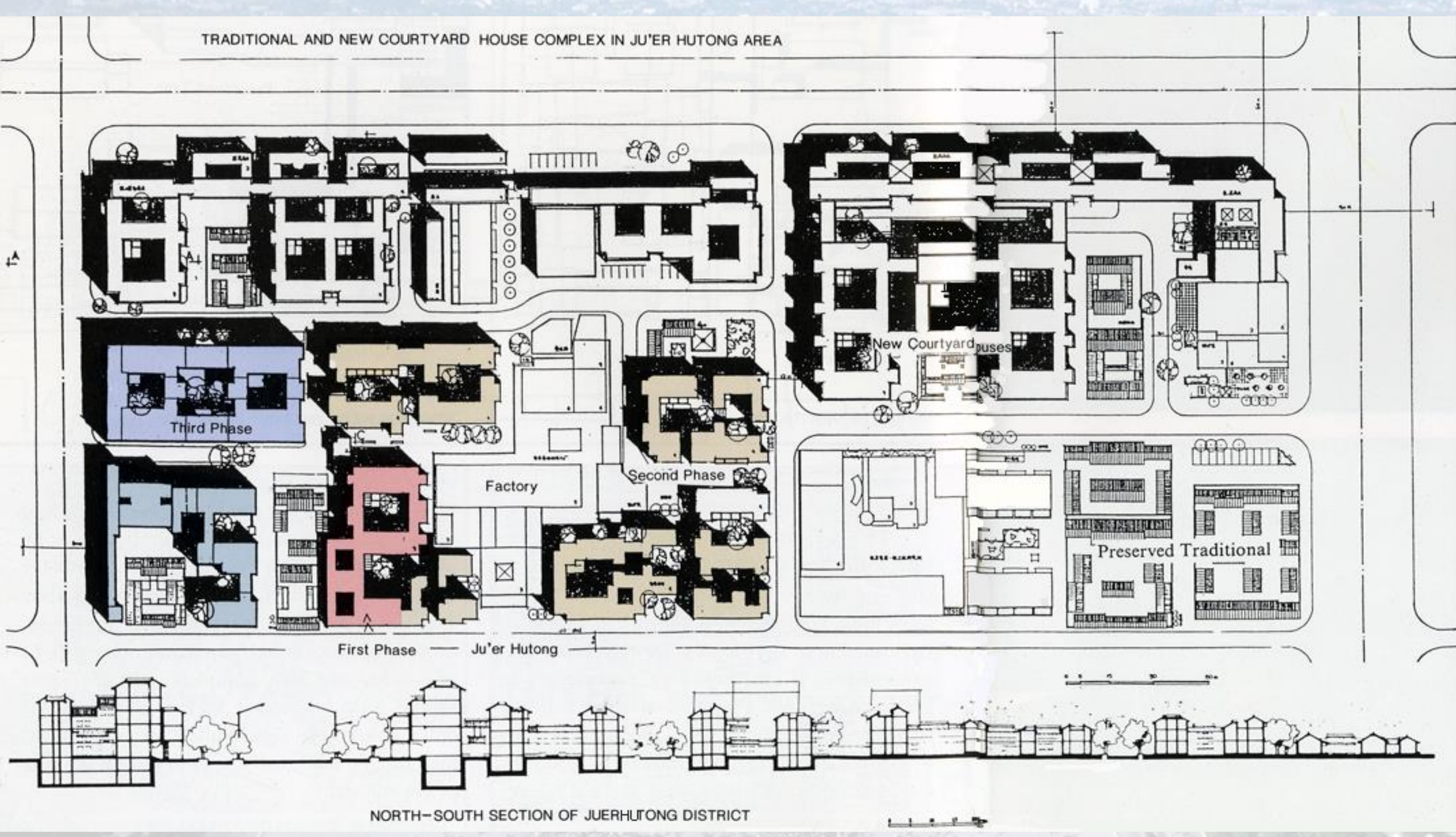

Juer Hutong new courtyard housing phased redevelopment plan. Source: Information Center, previously Resources Center, School of Architecture, Tsinghua/Qinghua University 


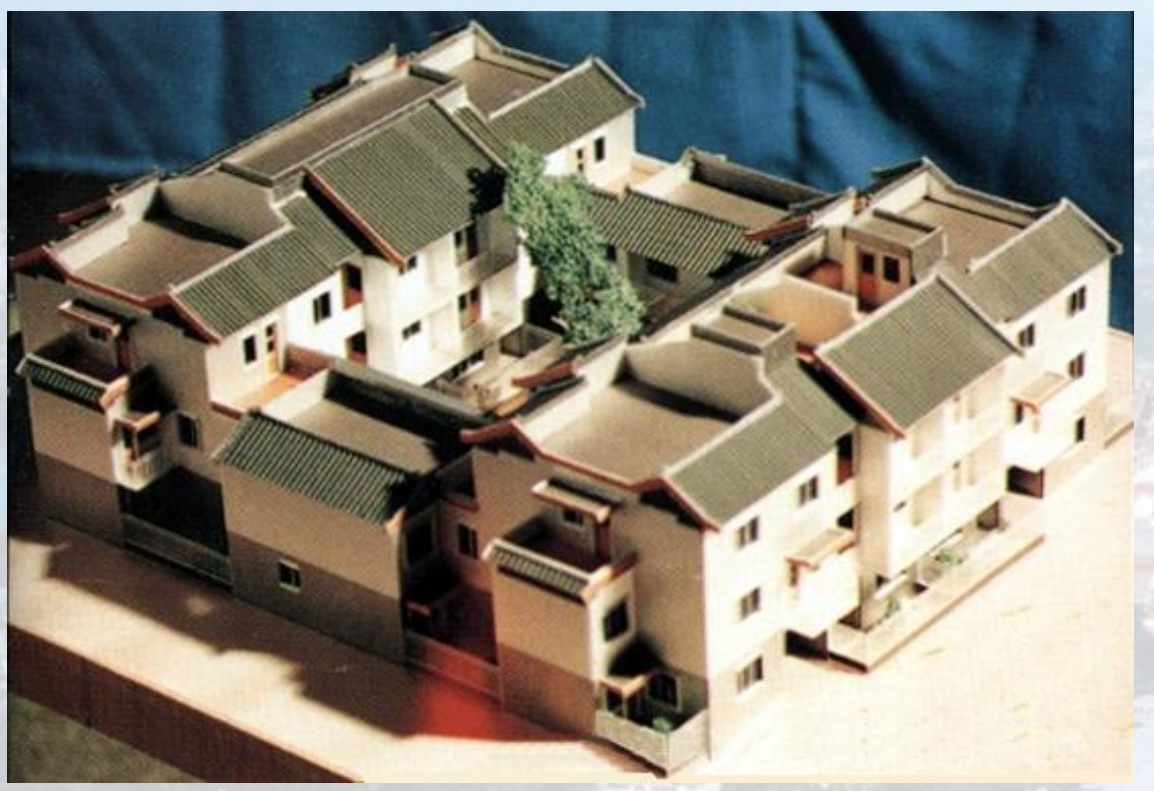

Source: Information Center, previously Resources Center, School of Architecture, Tsinghua/Qinghua University

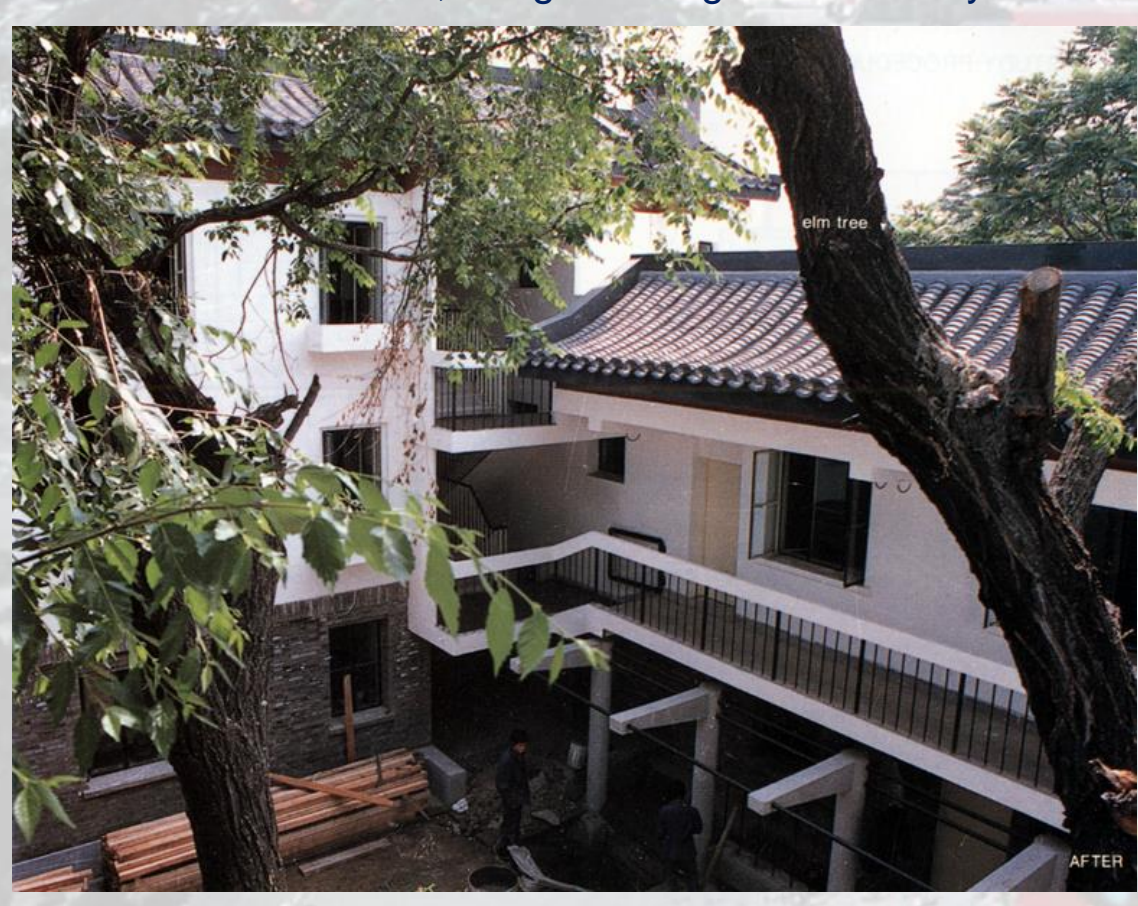

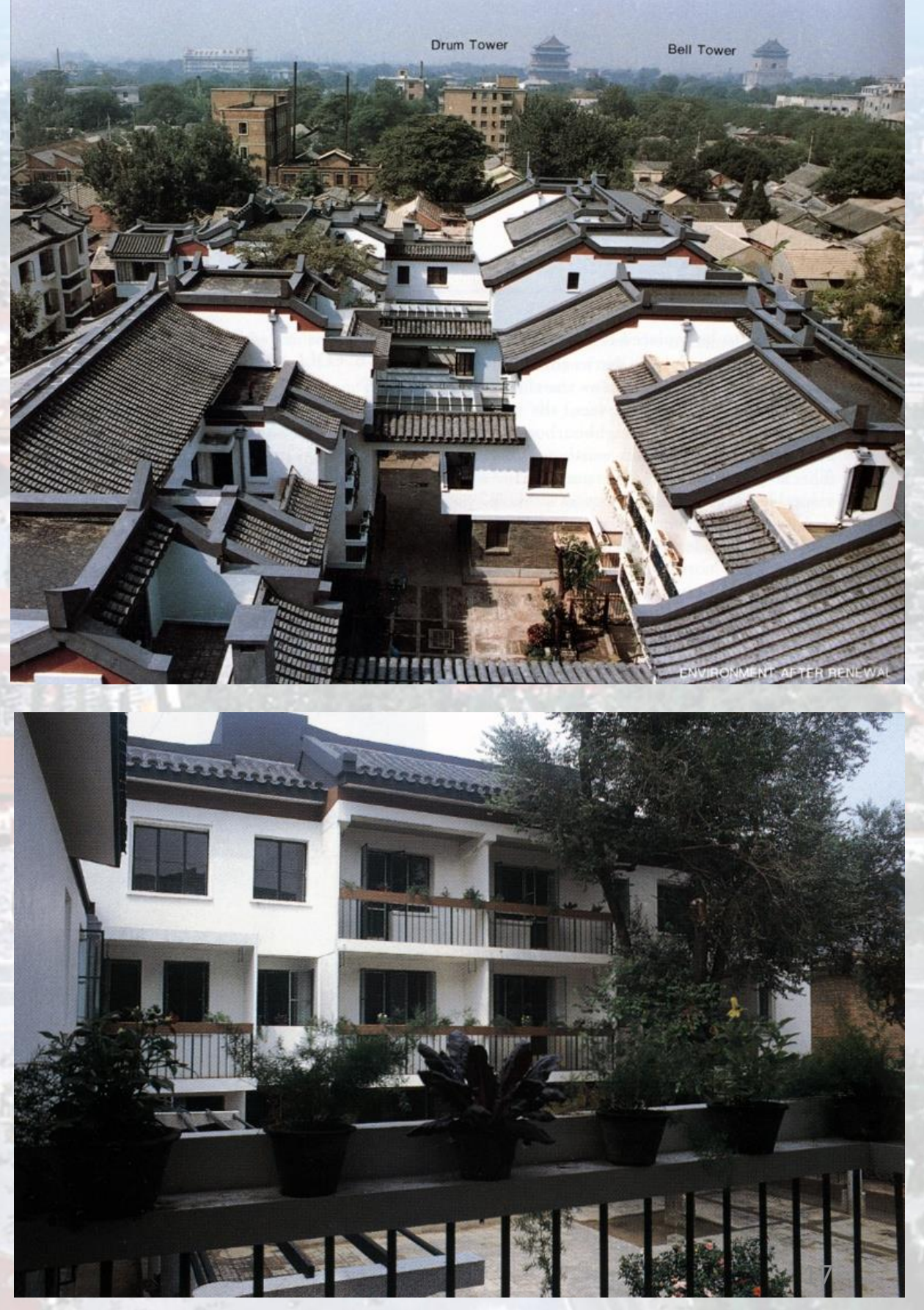




\section{Juer Hutong New Courtyard A: Small and Big}
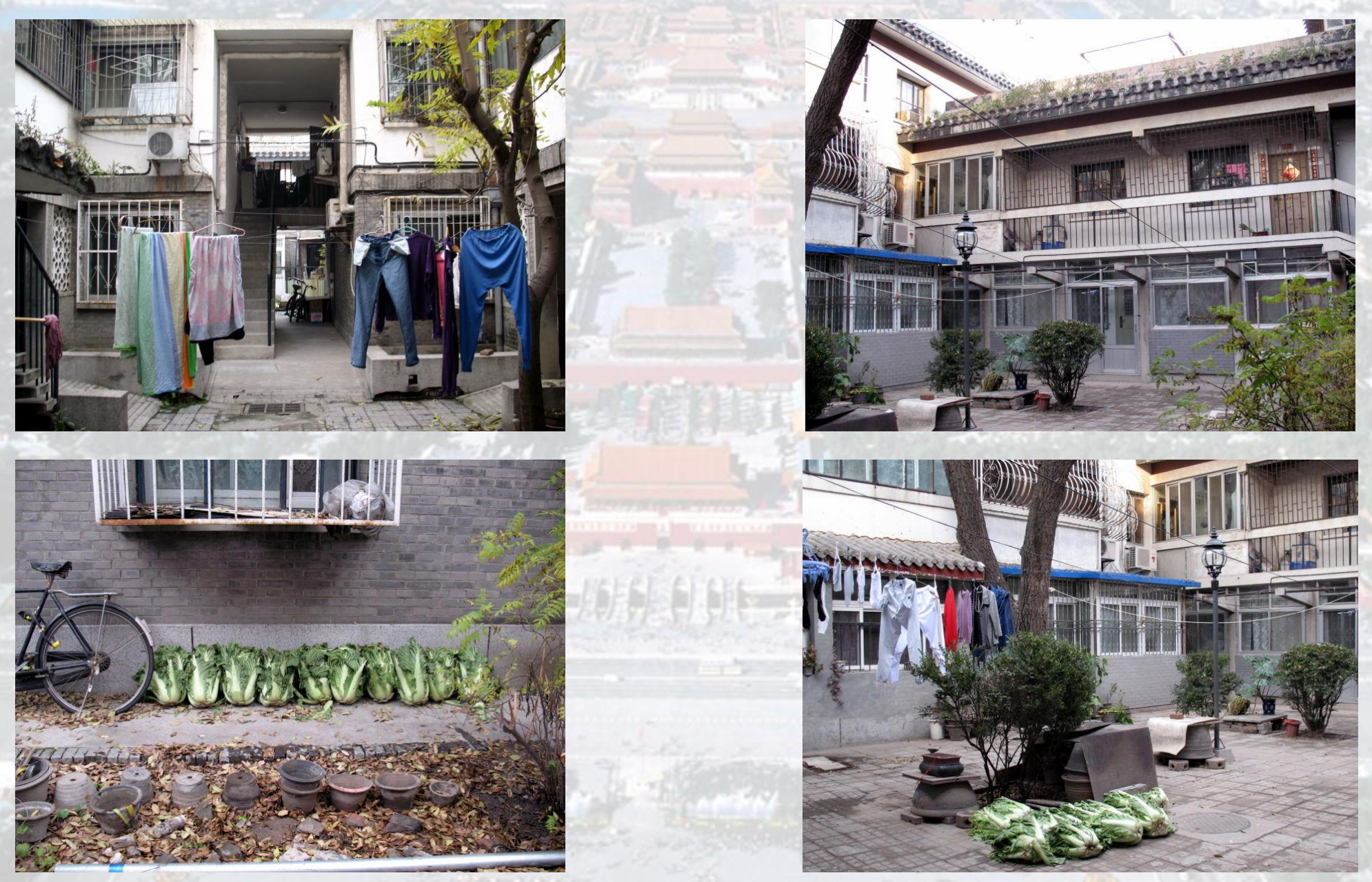


\section{Juer Hutong New Courtyards C, D, E}
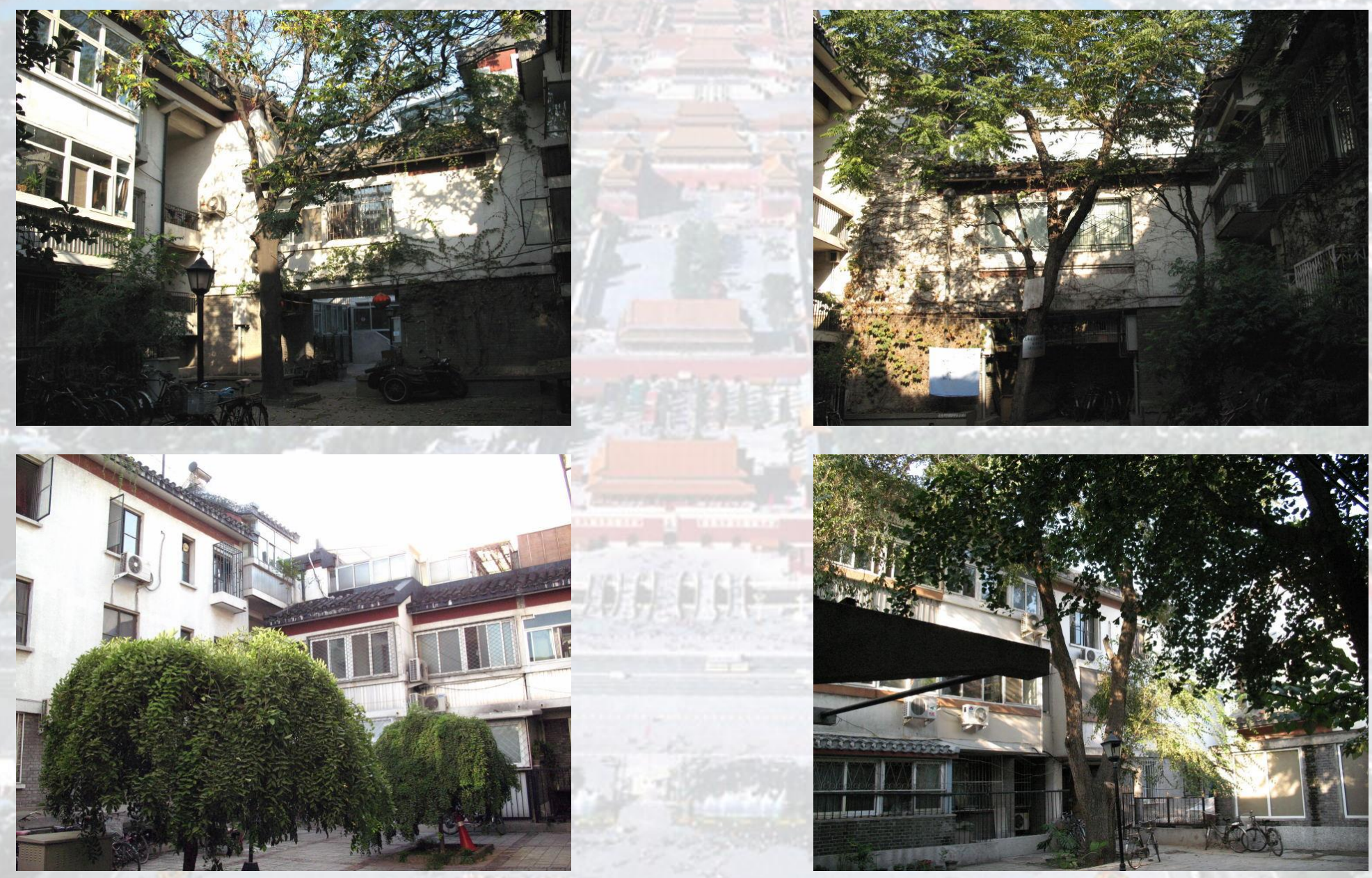


\section{Suzhou's City Planning}

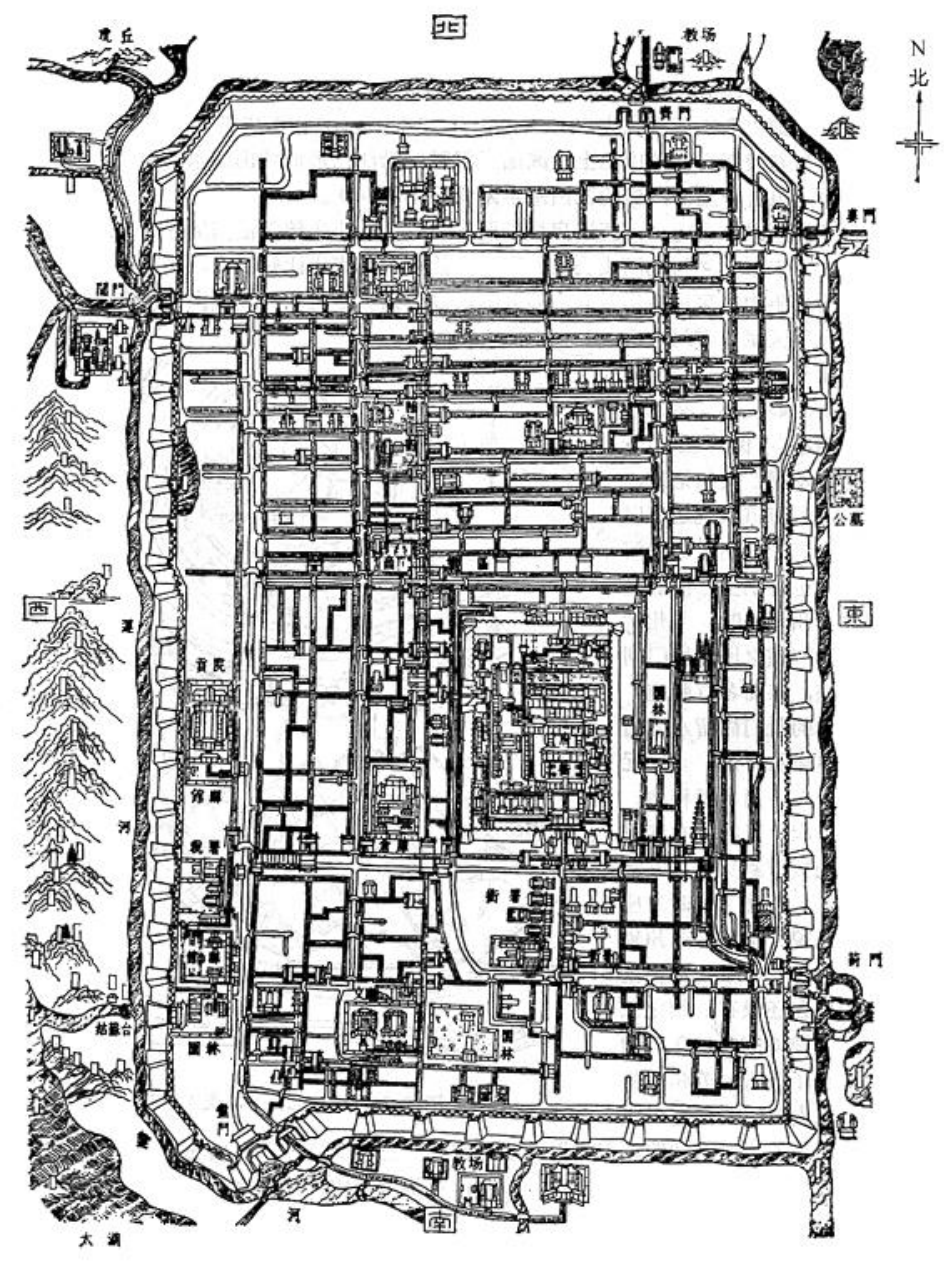

Pingjiang map (dated 1229) from a stone stele showing a double-chessboard, road-river system. Source: History of Chinese Architecture, 1986/2009, p. 56
UNESCO World Heritage Committee has added nine classical Suzhou gardens to their list. Suzhou's private gardens with spontaneous layouts enclosed within courtyard house compounds reflect the Daoist principle of "harmony with nature." 


\section{Traditional Courtyard Houses in Suzhou}

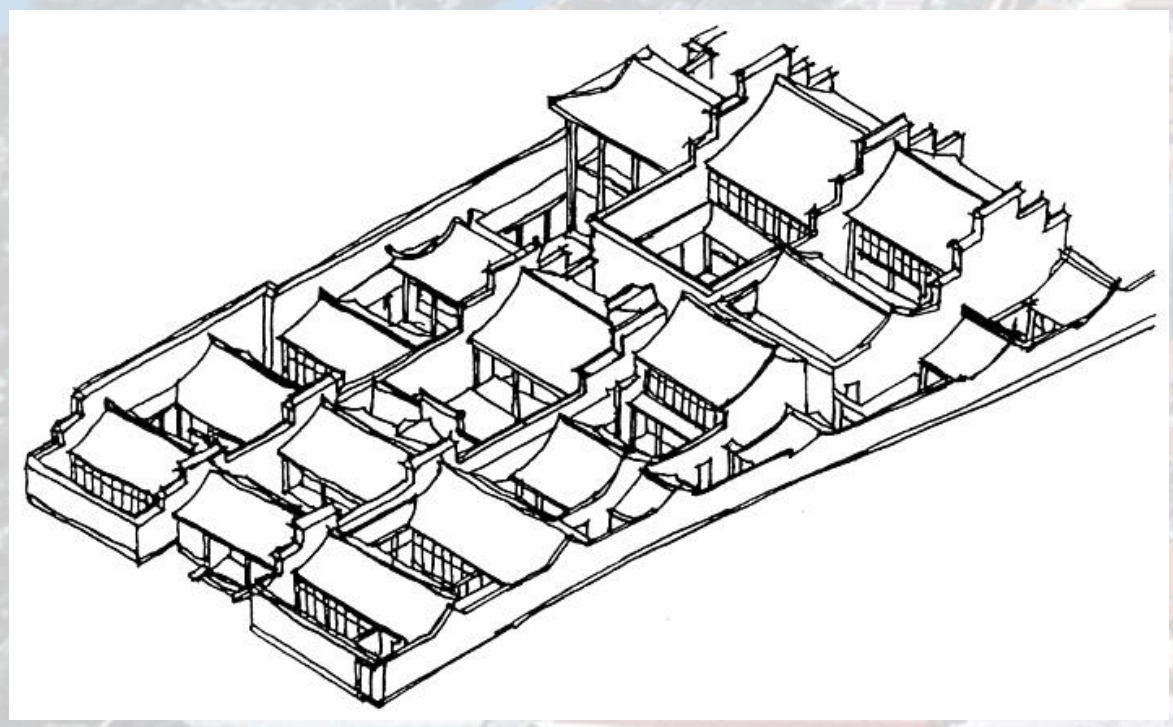

A large classical courtyard house in Suzhou. Source: Wu, 1991, p. 58

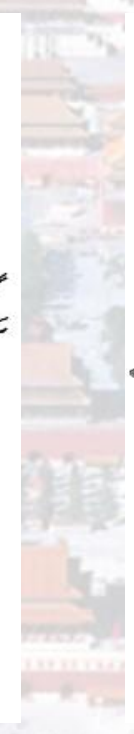

A computer model of classical Suzhou courtyard house. Source: Donia Zhang 2015, p. 31 


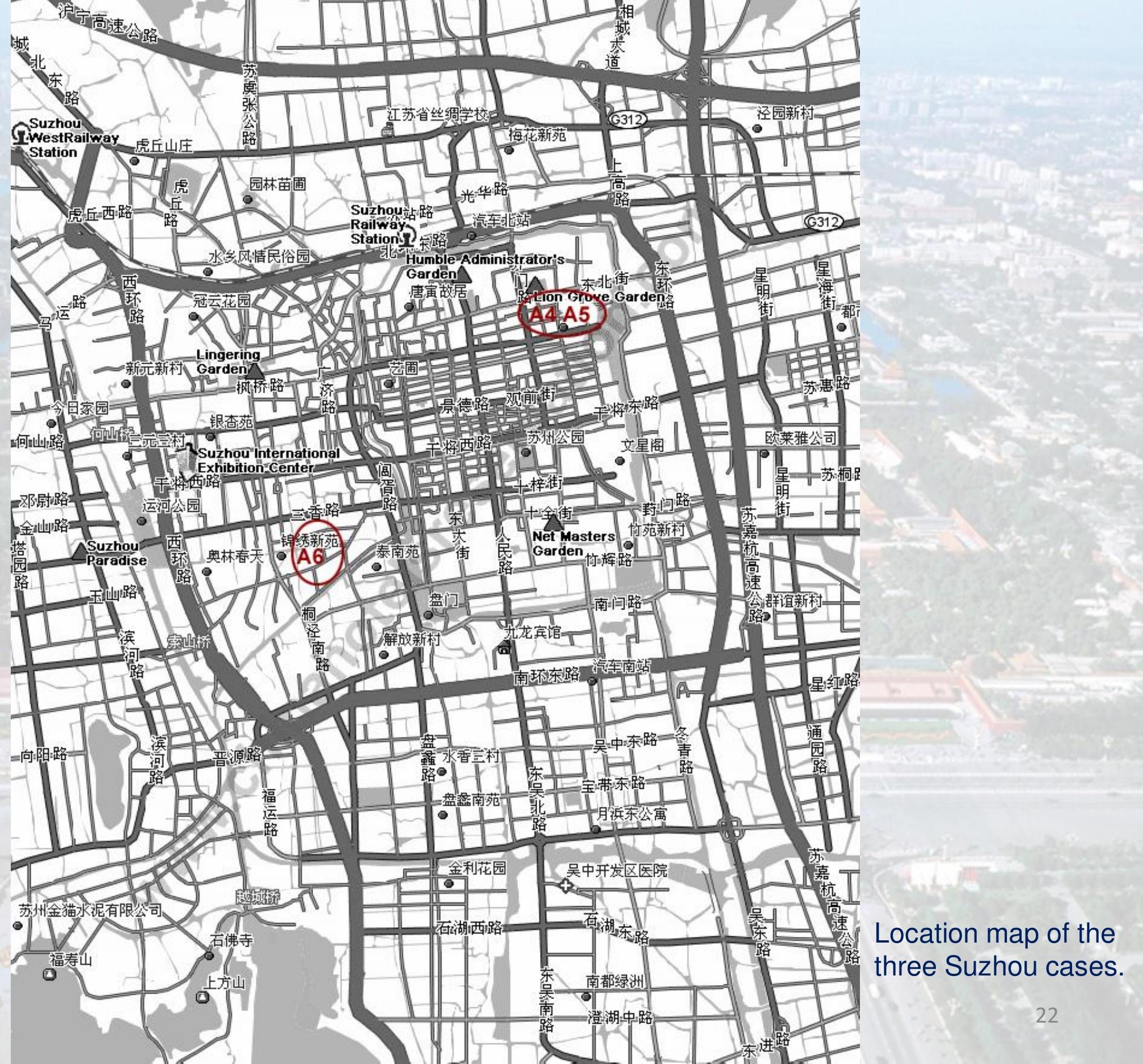


New Courtyard Housing built in Suzhou since the 1990s All Photos by Donia Zhang 2007

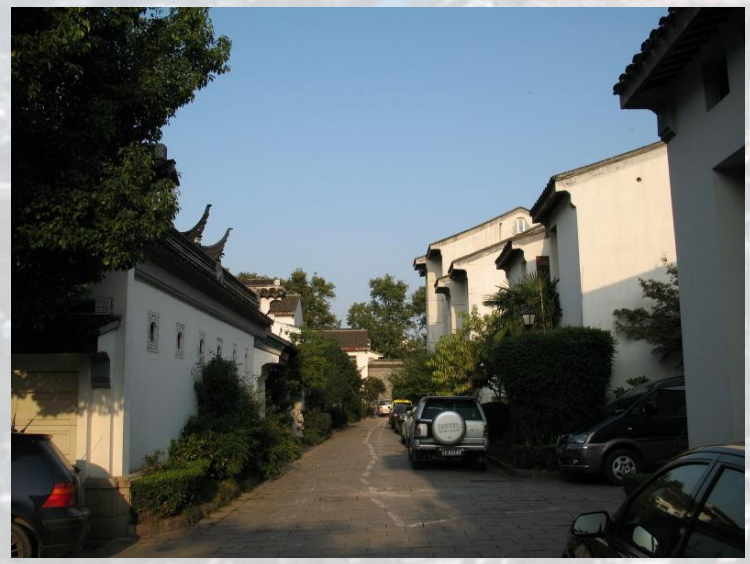

Tongfangyuan

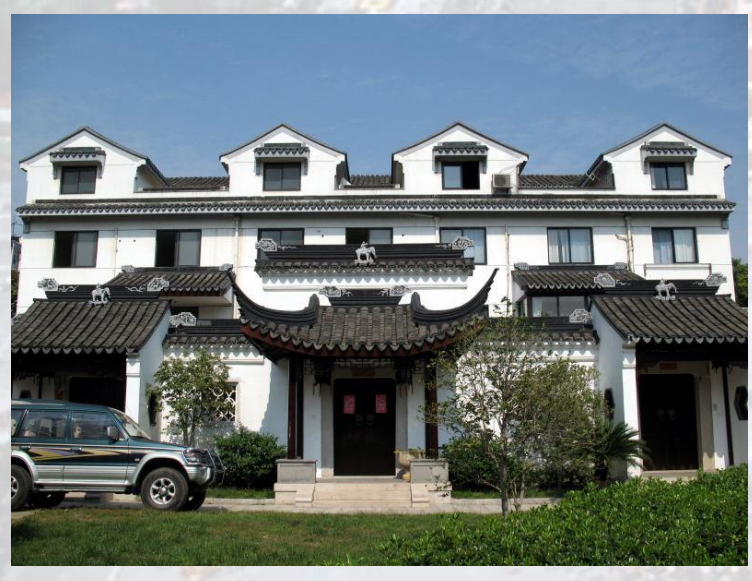

Jiaanbieyuan

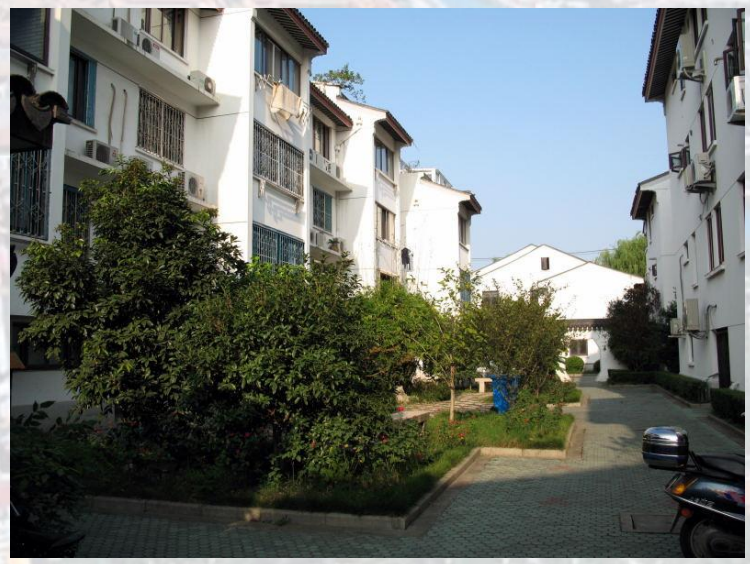

Shilinyuan

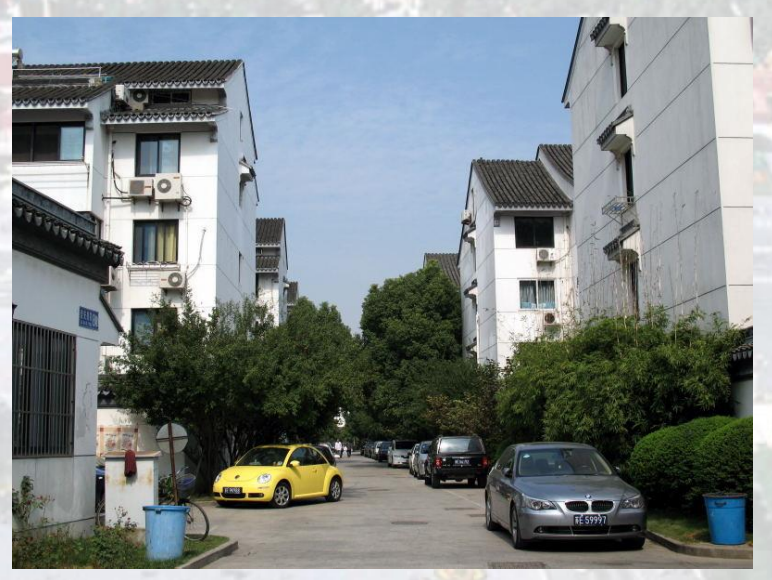

Jiaanbieyuan 

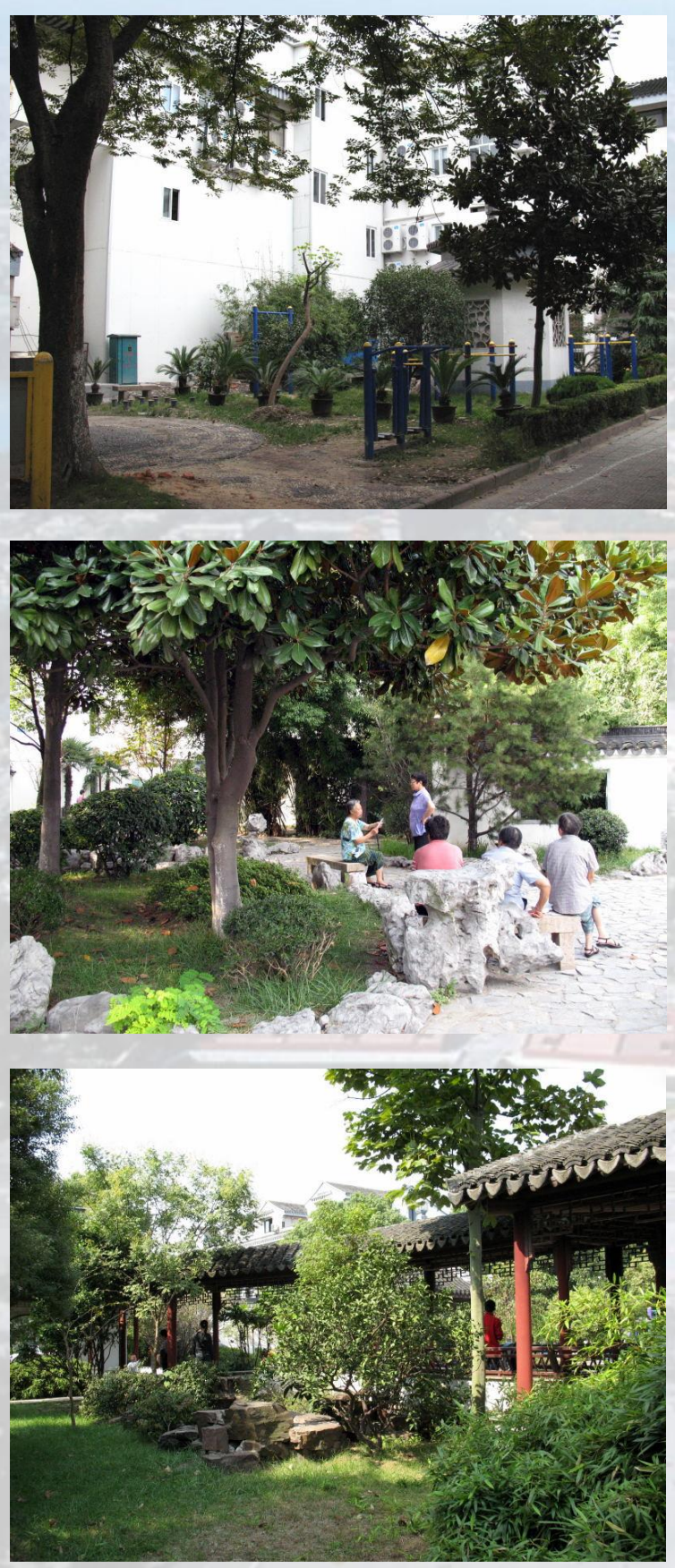

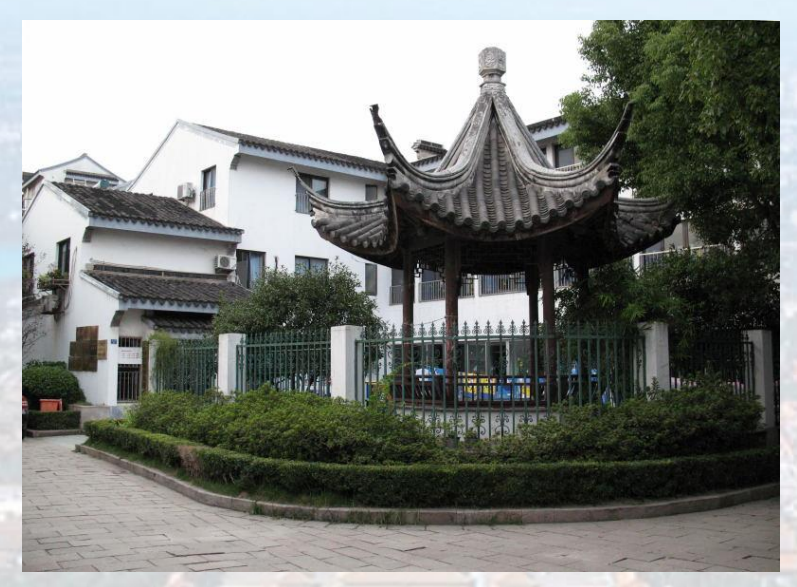

New Communal

Central Gardens in the Suzhou Cases

All Photos by Donia Zhang 2007
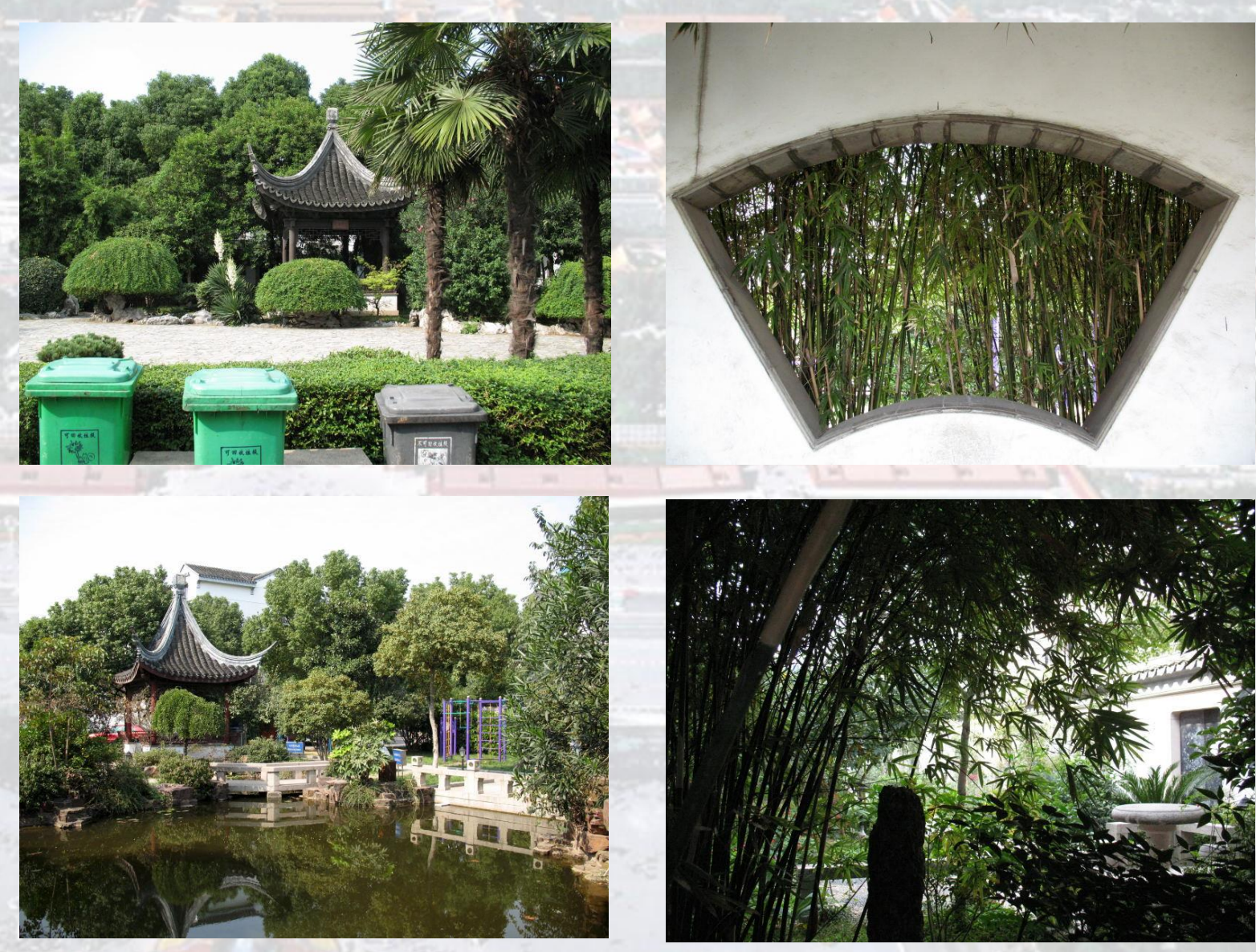


\section{New Private Courtyard Gardens in the Suzhou Cases All Photos by Donia Zhang 2007}

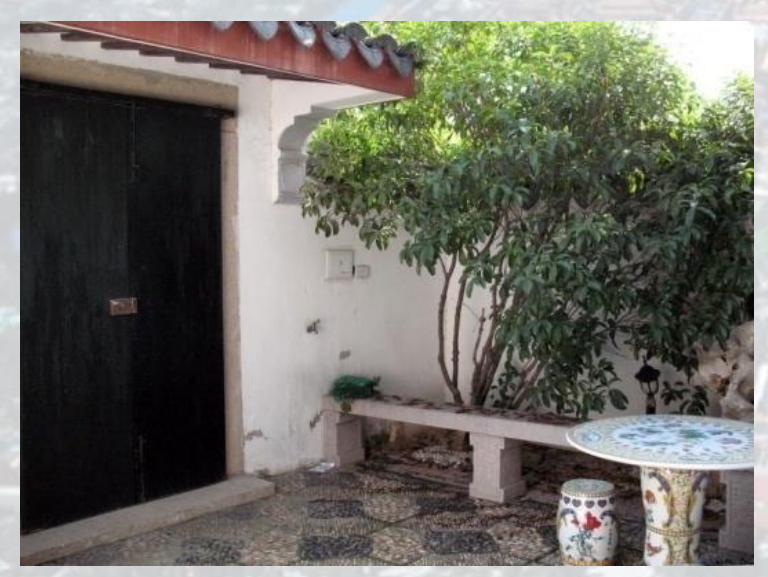

Shilinyuan

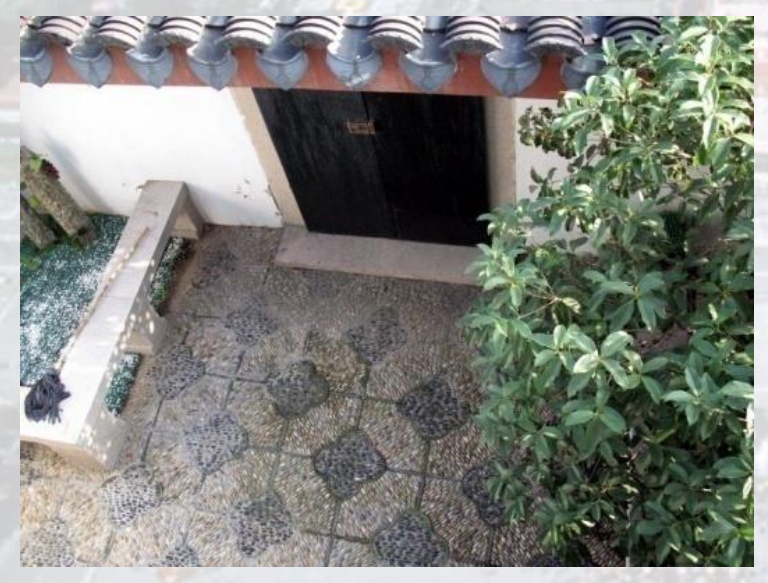

Shilinyuan

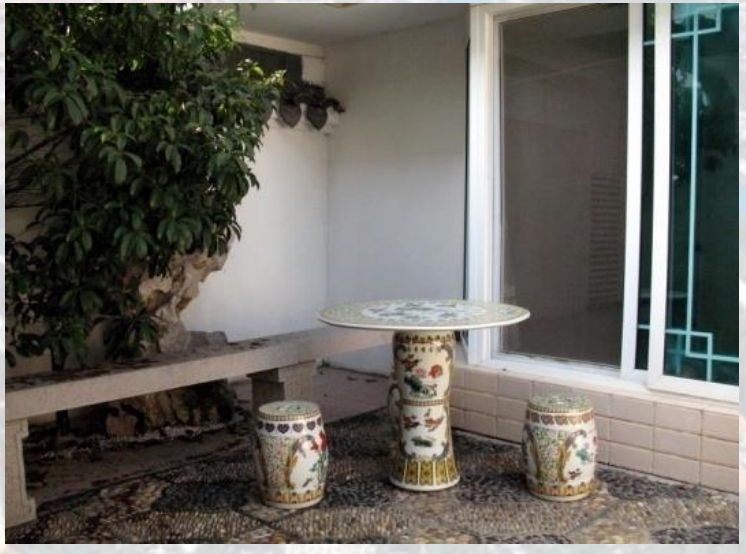

Shilinyuan

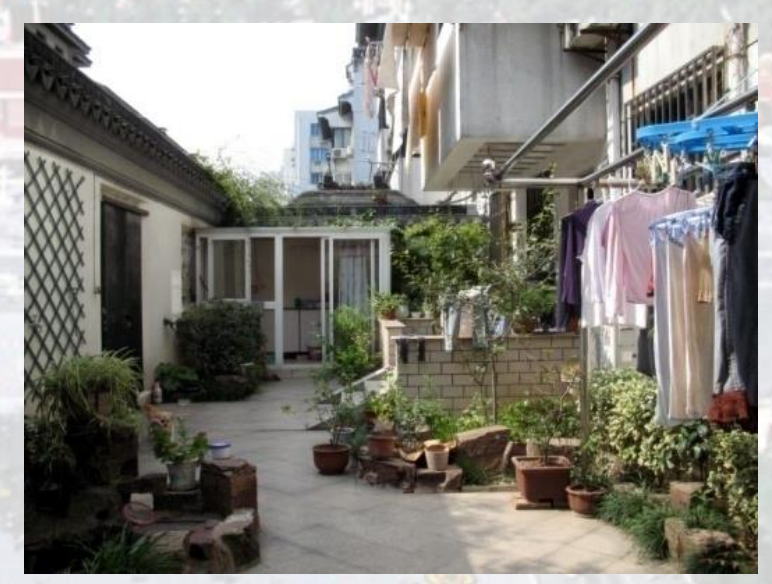

Jiaanbieyuan 


\section{Huayanghuayuan Private Courtyard Garden}

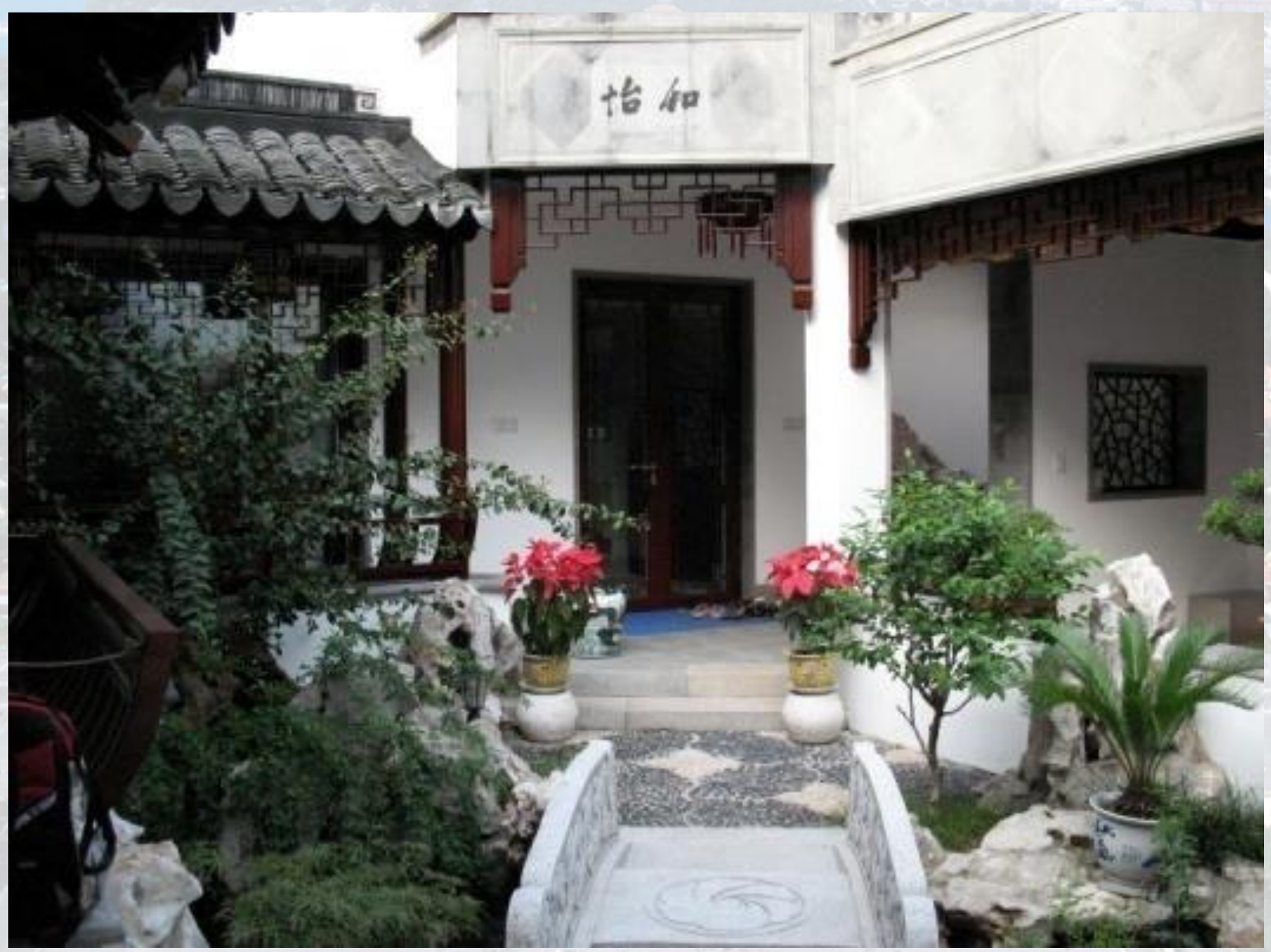




\section{Huayanghuayuan Private Courtyard Garden}

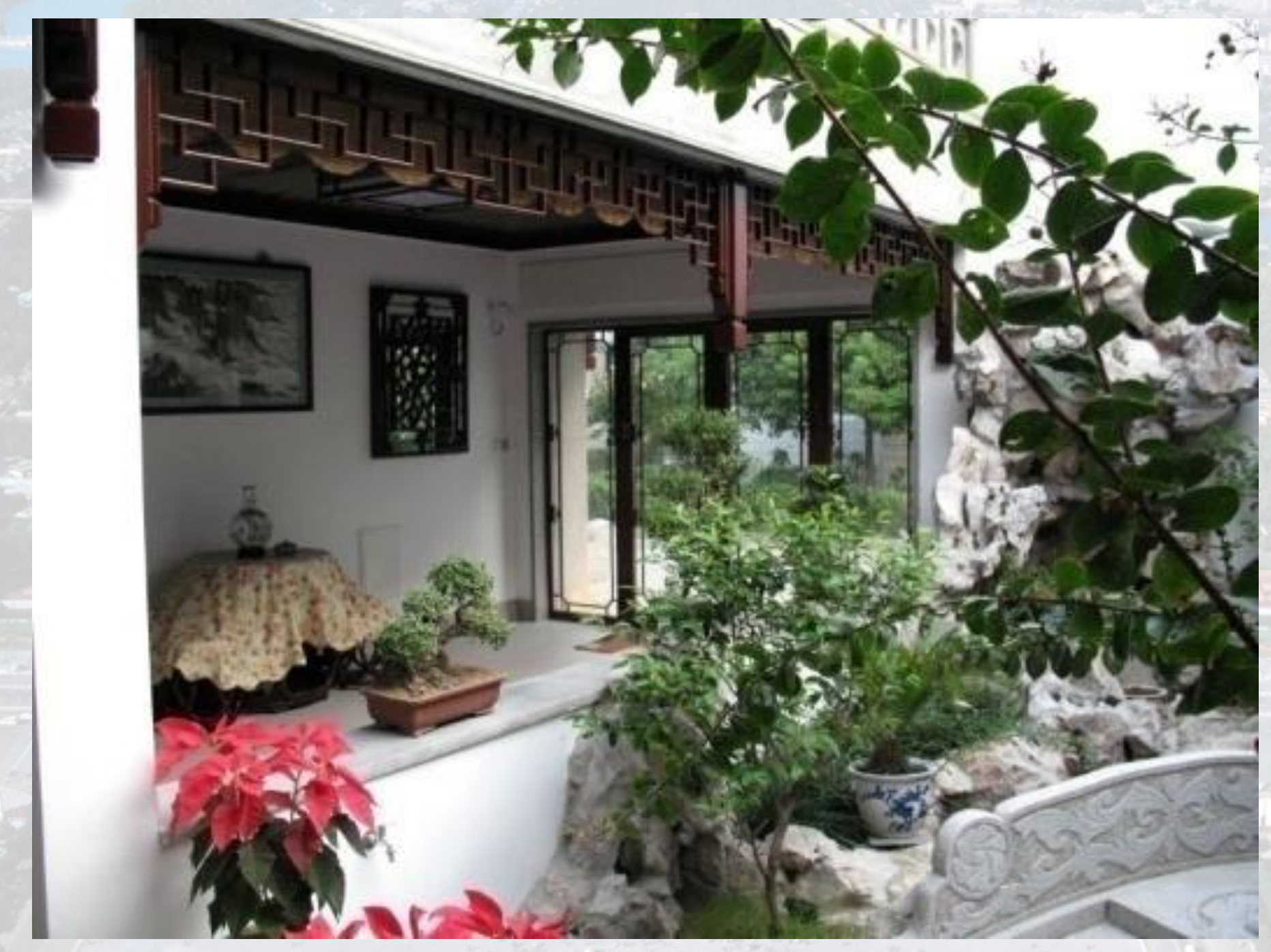




\section{Huayanghuayuan Private Courtyard Garden}

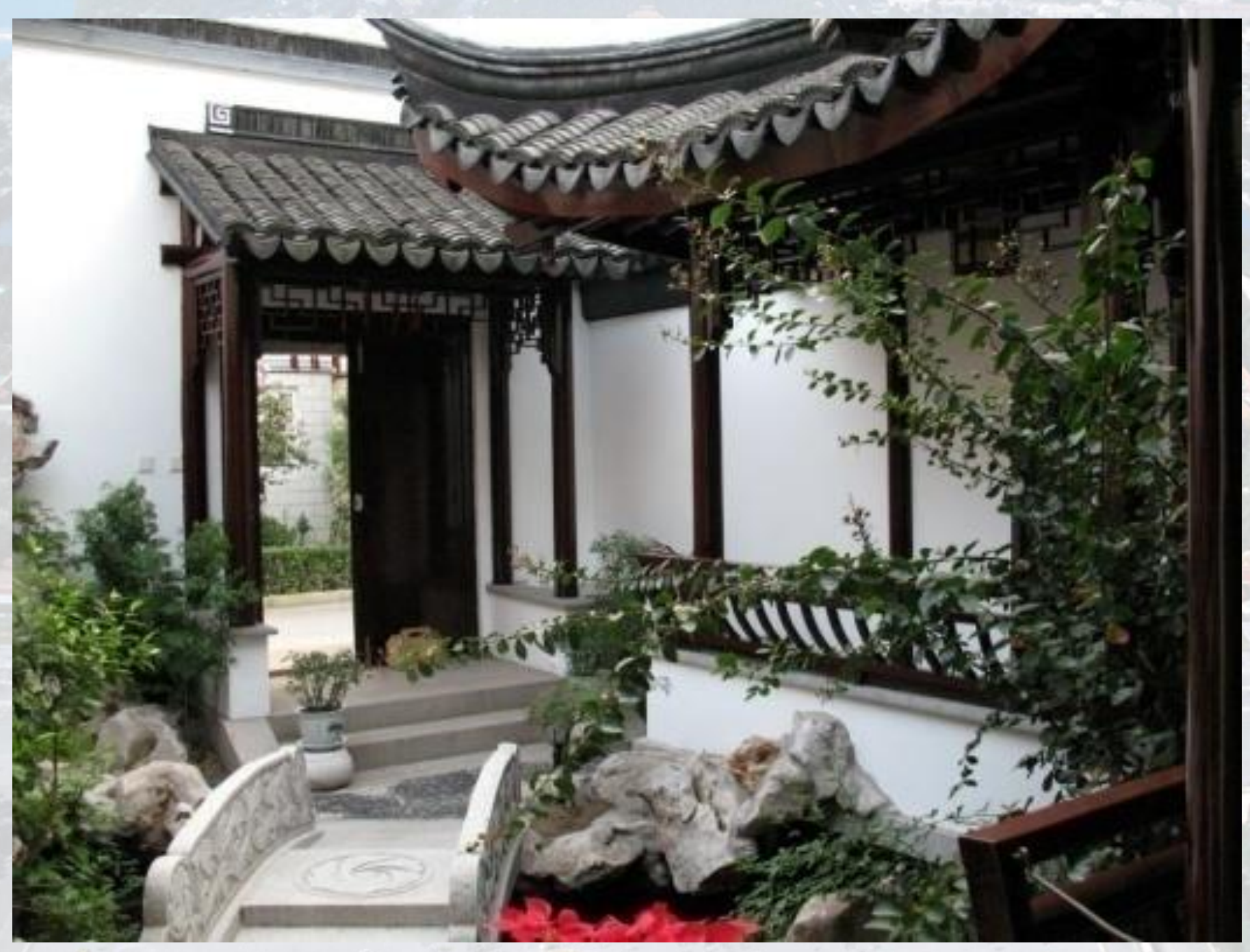




\section{Form and Space of the New Courtyard Housing}

(. The results reveal that the new courtyards are generally too small to admit enough sunlight

(.) The ratio of building height to distance should be at least 1:3 for Beijing (Zhang, 2006, 2011) and 1:1.3 for Suzhou

(. The interior spaces of new courtyard housing are generally small in Beijing Nanchizi and Juer Hutong, they are larger and more satisfactory in Suzhou Shilinyuan and Jiaanbieyuan

(2) Interior space of $120-180$ sqm per unit for a 3-4-person household is generally satisfactory

(. Most residents prefer to live in low-rise housing of 1-3 storeys for practical reasons, and living close to the earth (Feng Shui) is still preferred

(1) Residents have expressed a preference for pitched roofs than flat ones because they have experienced better thermal performance of pitched roofs 


\section{Social Cohesion and Cultural Activities in the New Courtyard Housing}

(. The findings also suggest that communal courtyards foster social interaction and private courtyards facilitate self-cultivation

(.) Neighborly relations are partly influenced by the form and space of the courtyard housing

(. Neighborly relations are partly influenced by a changing and polarizing society, socio-economic differences, housing tenure, modern lifestyles, community involvement, common language, cultural awareness, and the cultural background of the residents

(.) The communal courtyards help sustain some traditional Chinese cultural activities. The primary function of a communal courtyard is to maintain health/natural healing

(.) Many cultural activities are much less or no longer partaken in the communal courtyards, likely due to such factors as time, climate, courtyard ownership, yard size, facilities, and so on 


\section{Courtyard Housing in North America}

- In North America, courtyard housing is rare but the number is rising

๑) Influenced by the "Garden City" movement, courtyard housing started in Toronto, Ontario, Canada as early as 1910

(.) The examples are the Three Streets Housing Cooperative (b. 1910), Bain Apartments Co-operative (former "Riverdale Courts," b. 1913-1920s), and Spruce Court Housing Co-operative (b. 1913-1926) 

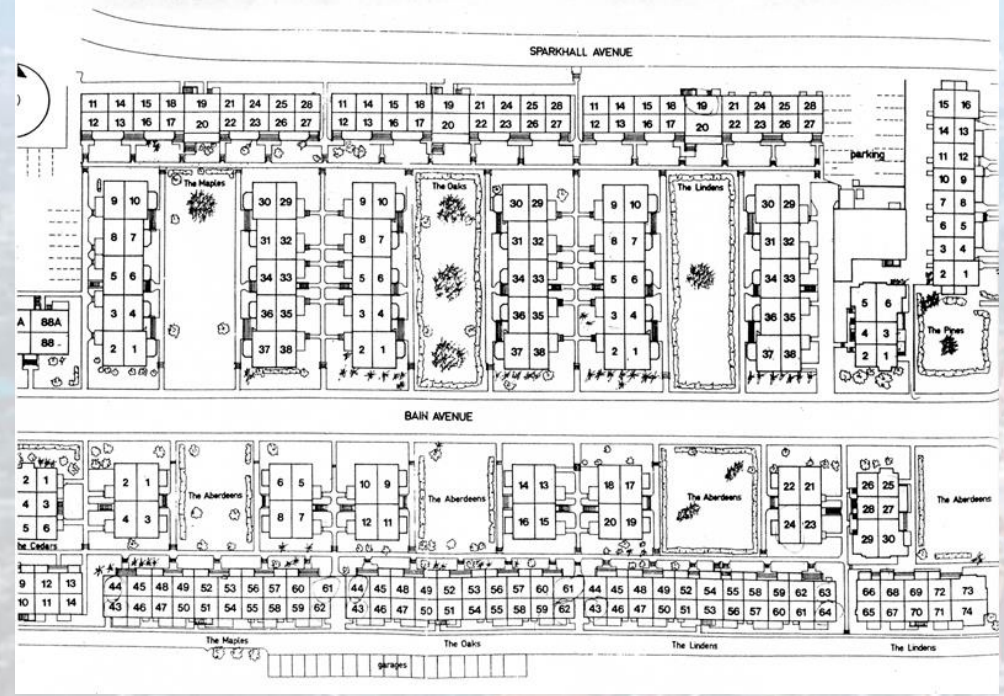

Site plan of the Bain Apartments Co-operative illustrating eight courtyards, Toronto, Ontario, Canada. Source: Bain Apartments Co-operative 2013

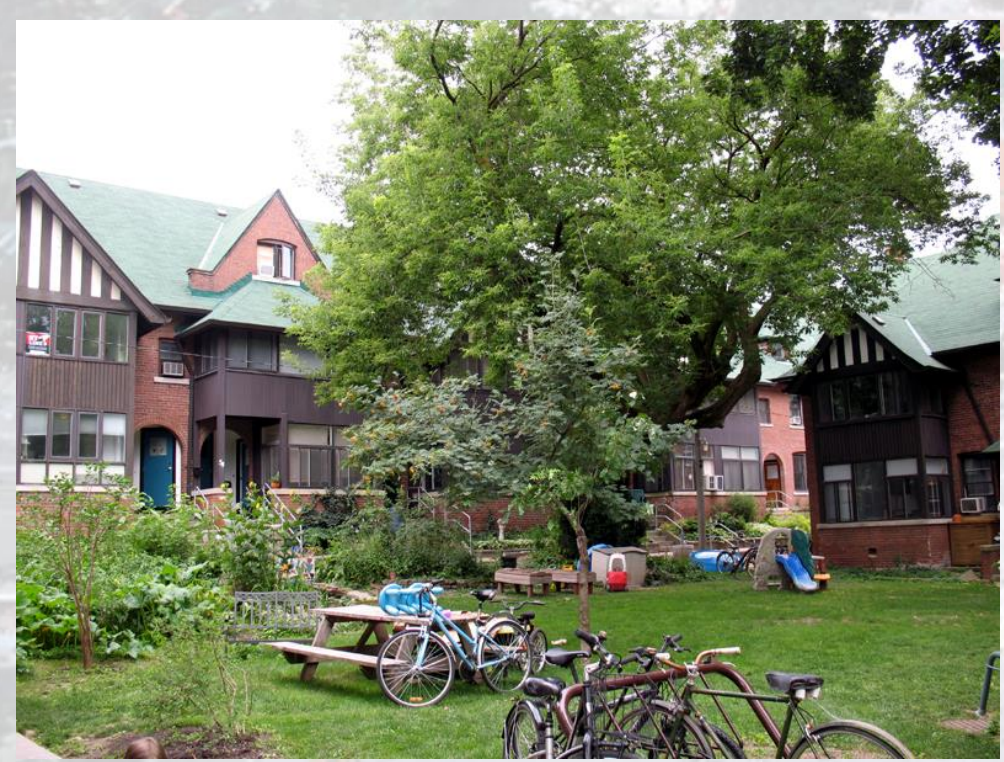

The South Lindens courtyard at the Bain Apartments Cooperative (b. 1913-1920s), Toronto, Ontario, Canada. Photo by Donia Zhang 2013

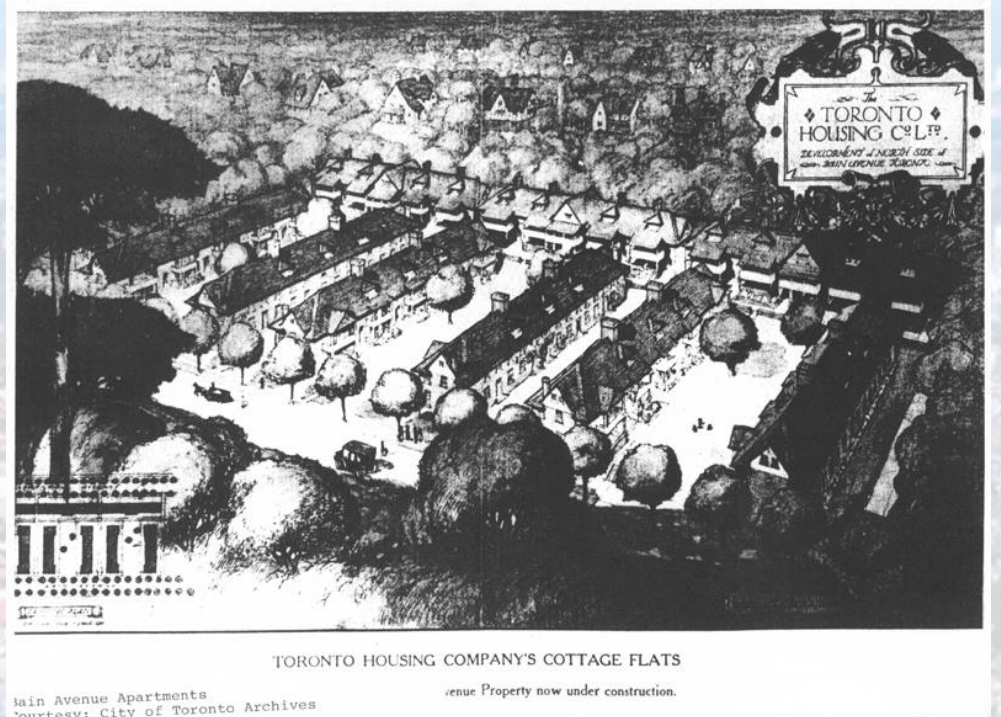

Aerial view of the Bain Apartments Co-operative (former 'Riverdale Courts,' b. 1913-1920s), Toronto, Ontario, Canada. Courtesy of the City of Toronto Archives

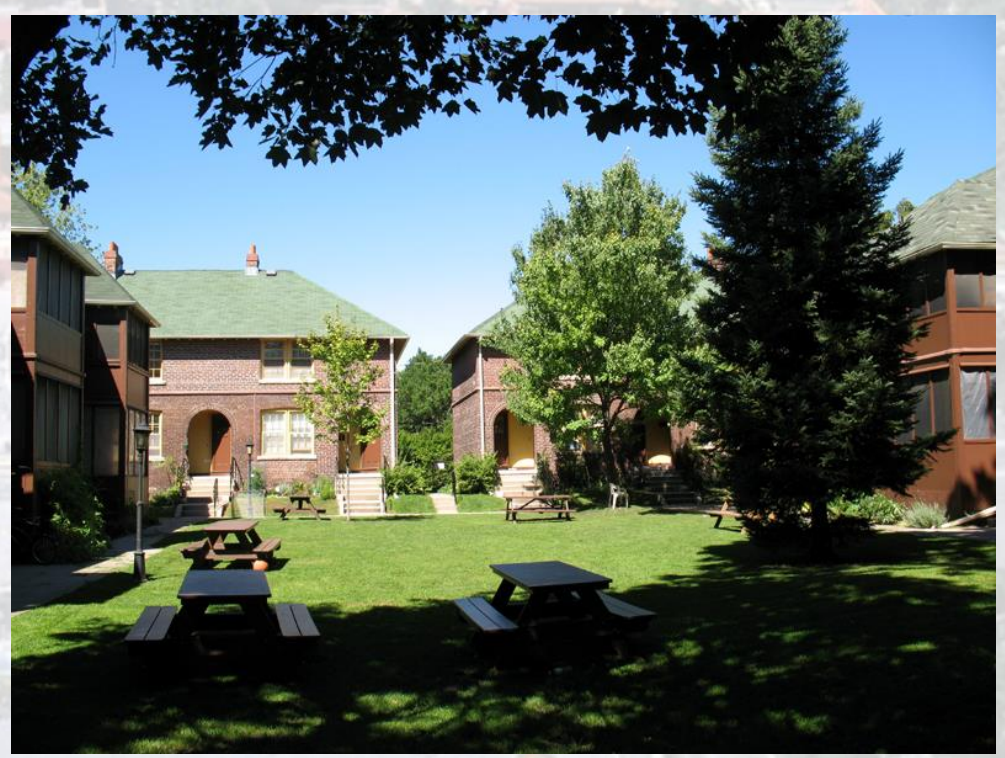

A courtyard at the Spruce Court Housing Co-operative (b. 1913-1926), Toronto, Ontario, Canada. Photo by Donia Zhang 2013 


\section{Courtyard Housing in North America (continued)}

(1) In California, courtyard housing was adapted from Spanish precedents and built in the 1920s-1930s. It then spread to the city of New Orleans, and some other places in the USA

๑. Beginning in the 1960s, new courtyard-style of housing was constructed in American cities. This housing type revived as part of the New Urbanism movement in the 1990s

(.) Most of these courtyard housing projects are in Mediterranean style, designed or restored by American architects Stefanos Polyzoides and his wife and partner Elizabeth Moule, who attempted to reconnect with Los Angeles history and improve the urbanism of the city 


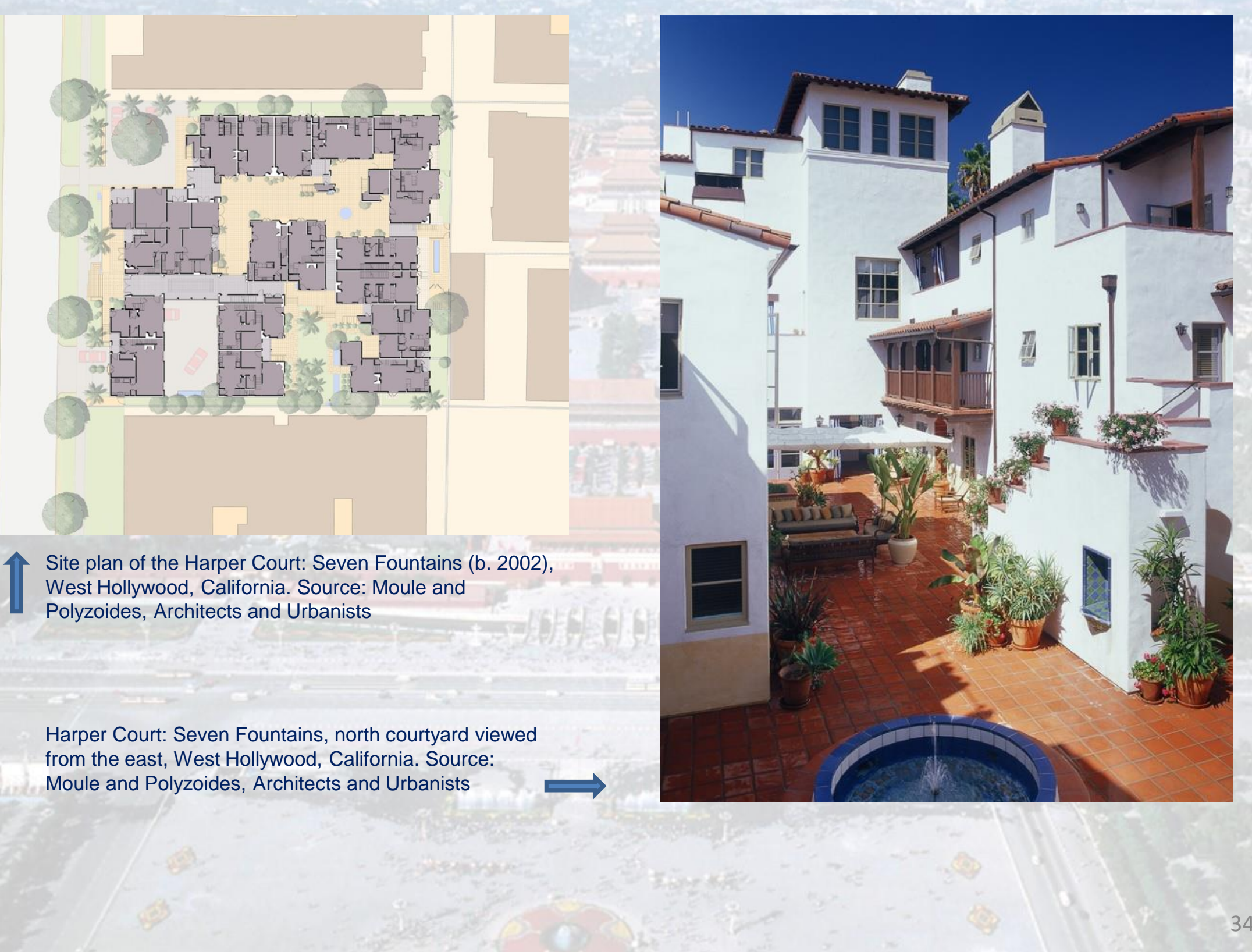




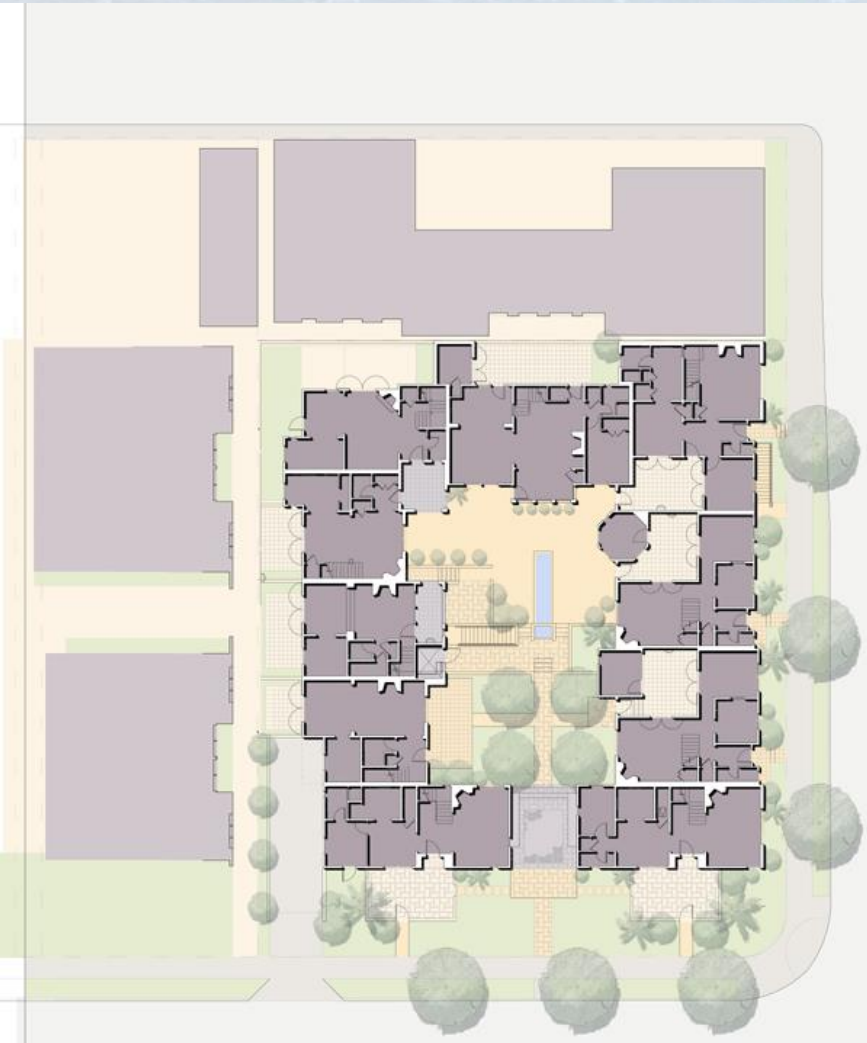

Site plan of the Meridian Court (b. 2004), Pasadena,

California. Source: Moule and Polyzoides, Architects and Urbanists

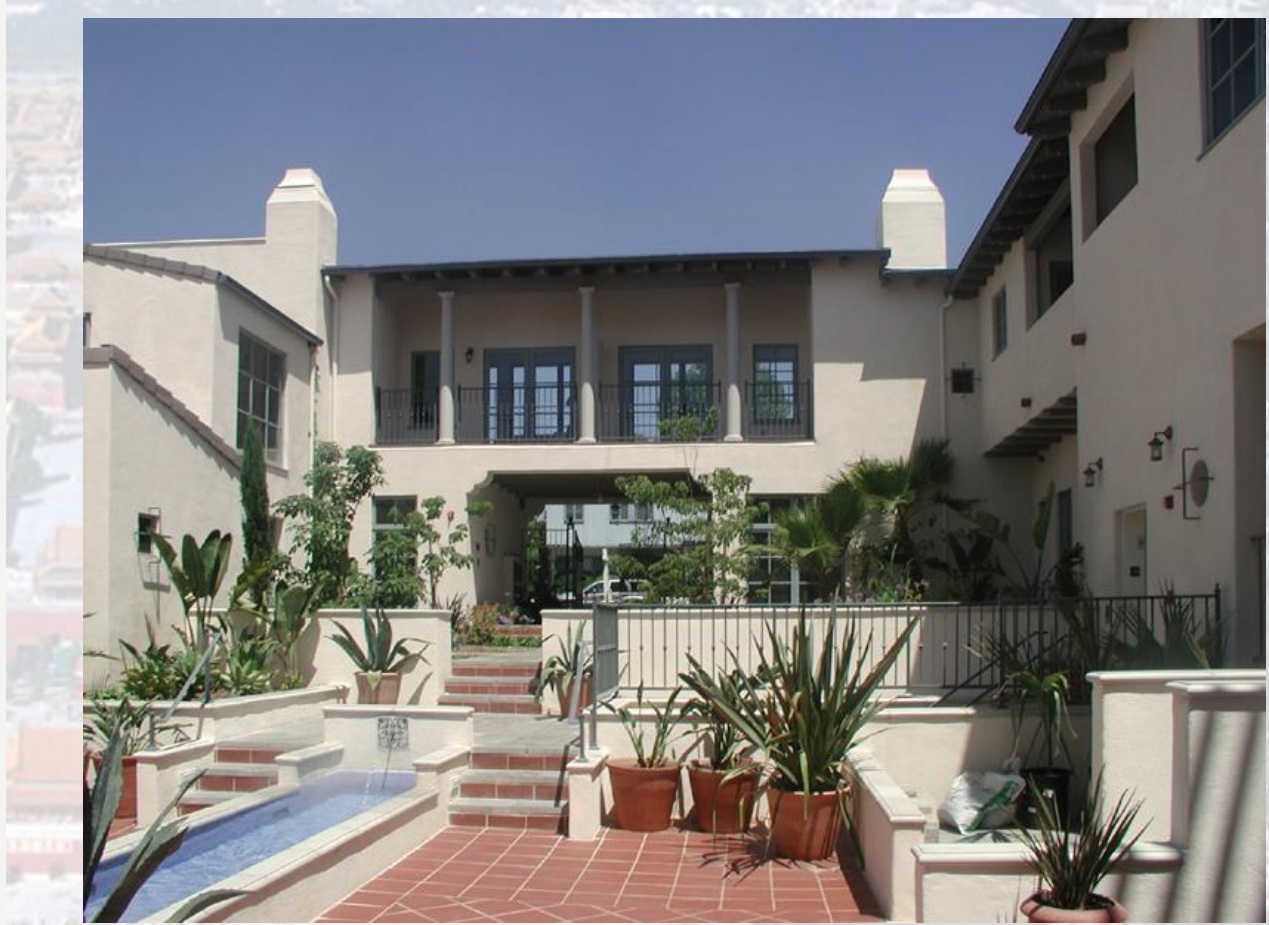

Meridian Court main courtyard, Pasadena, California. Source: Moule and Polyzoides, Architects and Urbanists 


\section{Courtyard Housing in North America (continued)}

(.) Since the 1980s, courtyard-style of housing revived in Canada, typically in the name of "co-operative housing" built by the Co-operative Housing Federation of Canada

๑. At the time of the survey (2013), 16 of $53(30 \%)$ co-operative housing in Toronto have courtyards

(.) The Canadian Cohousing Network (CCN, formed in 1992) is part of a global cohousing initiative and courtyard spaces are fundamental to the cohousing design concept

(2) At the time of the study (2013-2016), CCN endorsed 24 cohousing projects across Canada, although some are still in the planning and development stages

(. In 2013, the Cohousing Association of the United States listed 213 cohousing communities on their website; in 2014, the number increased to 234; and by the end of 2015, it increased to 289 


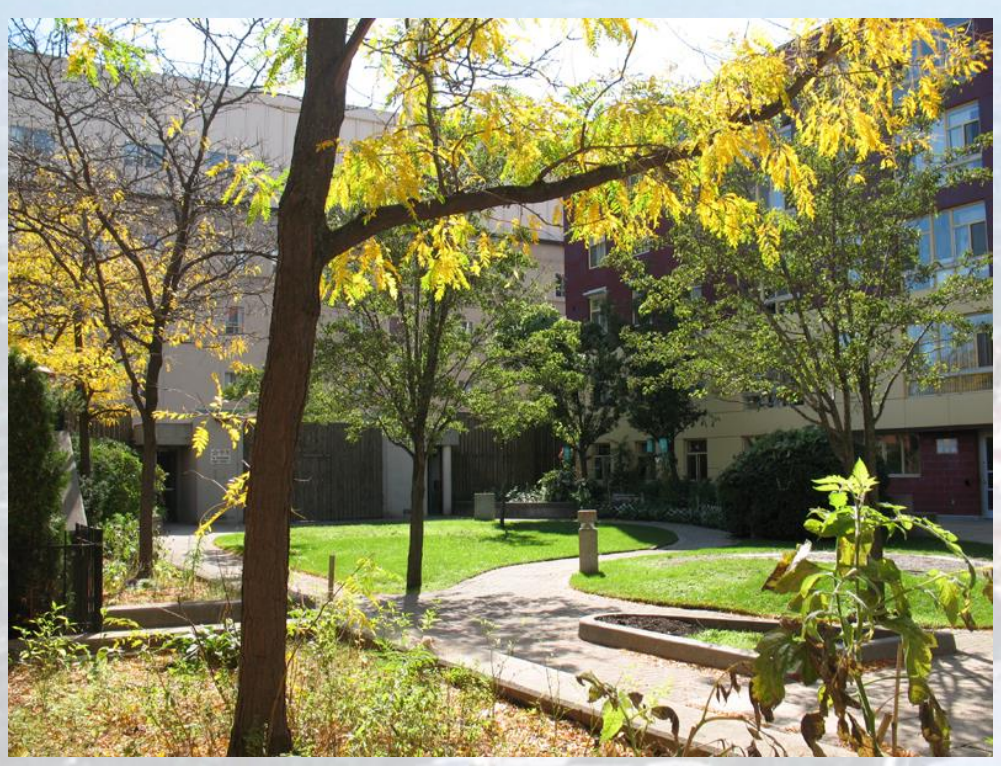

Jenny Green Co-operative Homes courtyard, Toronto,

Ontario, Canada. Photo by Donia Zhang 2013

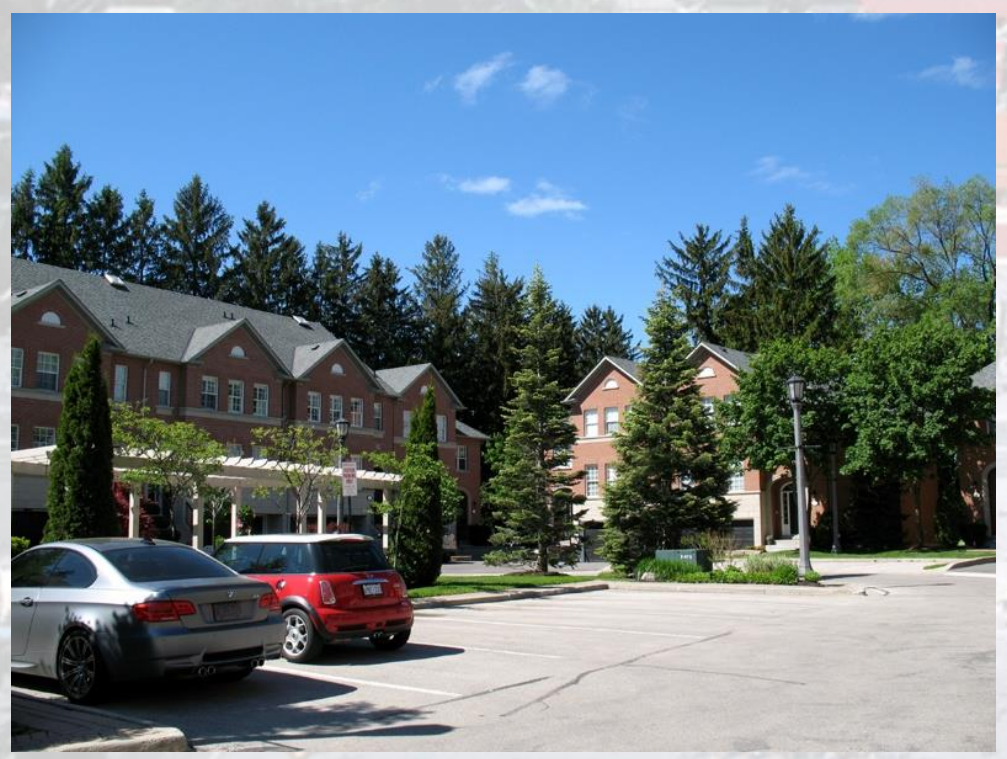

Kingsmere courtyard (b. 1998), Thornhill, Ontario, Canada. Photo by Donia Zhang 2013

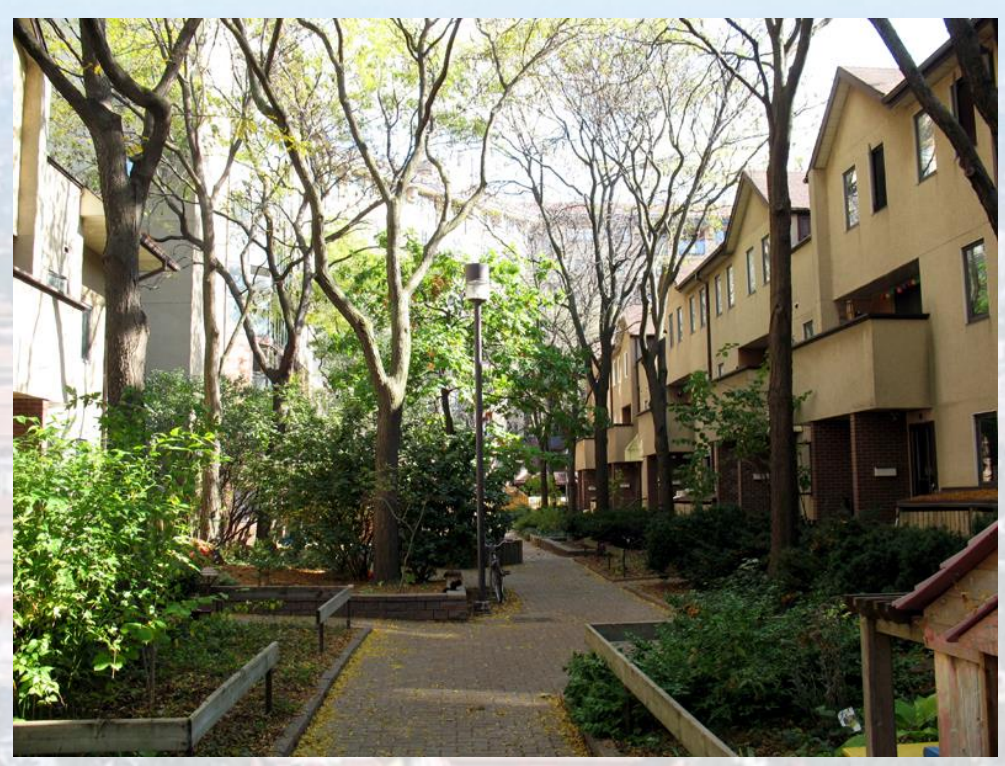

Oak Street Housing Co-operative courtyard (b. 1987), Toronto, Ontario, Canada. Photo by Donia Zhang 2013

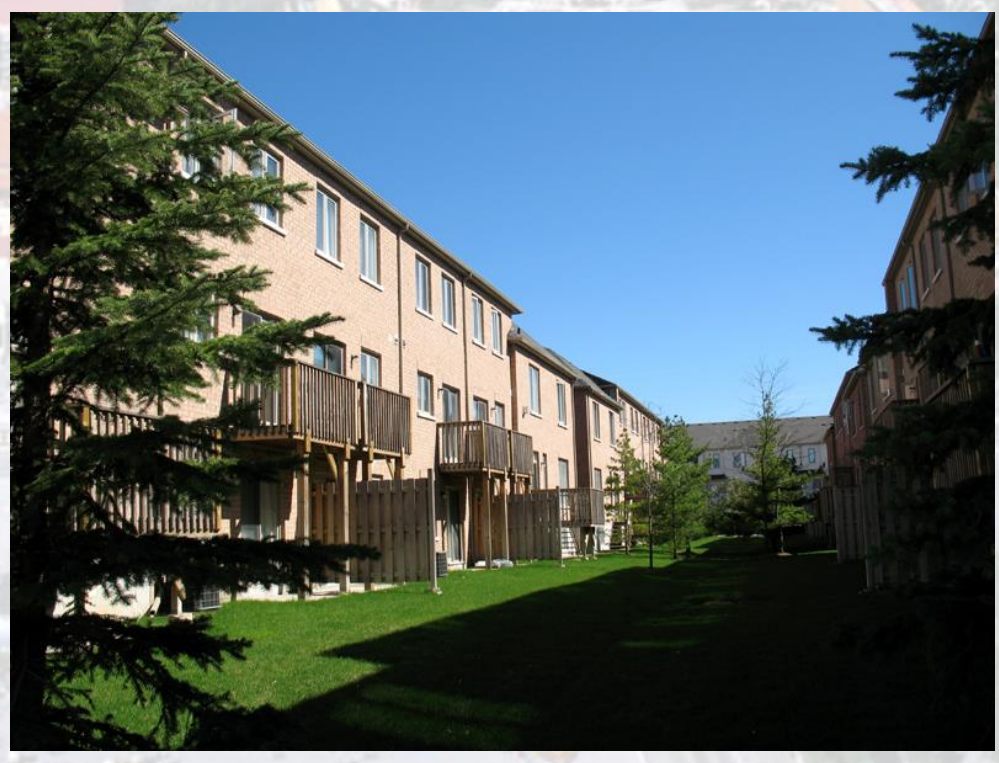

Bristol Court (b. 2003), Richmond Hill, Ontario, Canada. Photo by Donia Zhang 2013 


\section{Courtyard Housing for Health and Happiness}

(. My 2013 research findings suggest that 21 percent $(n=314)$ of the ethnic Chinese survey respondents (who were 16 years or older) preferred a courtyard house/housing

๑. Although only 11 percent $(n=37)$ of the ethnic Chinese interviewees wanted a courtyard house, 70 percent of them favored a communal courtyard

๑. The results show that ethnic Chinese in North America generally get along well with their neighbors, but mainly on a superficial level. In-depth communications would require more time and efforts on the parts of the neighbors, as well as a fenceless common space, such as a courtyard, to promote social interaction 


\section{Courtyard Housing for Health and Happiness (continued)}

(. The interviews with non-Chinese residents $(n=20)$ living in cooperative housing in Toronto and cohousing across Canada reveal that the things that make them happy about the communal courtyards include: courtyards as children's playgrounds, courtyards as landscaped gardens, courtyards as social spaces, and co-operative property management

(.) The things that make them unhappy include: differences in lifestyles, lack of private backyards, lack of volunteerism, and neighbor conflicts 


\section{Proposals for New Courtyard Garden Houses}

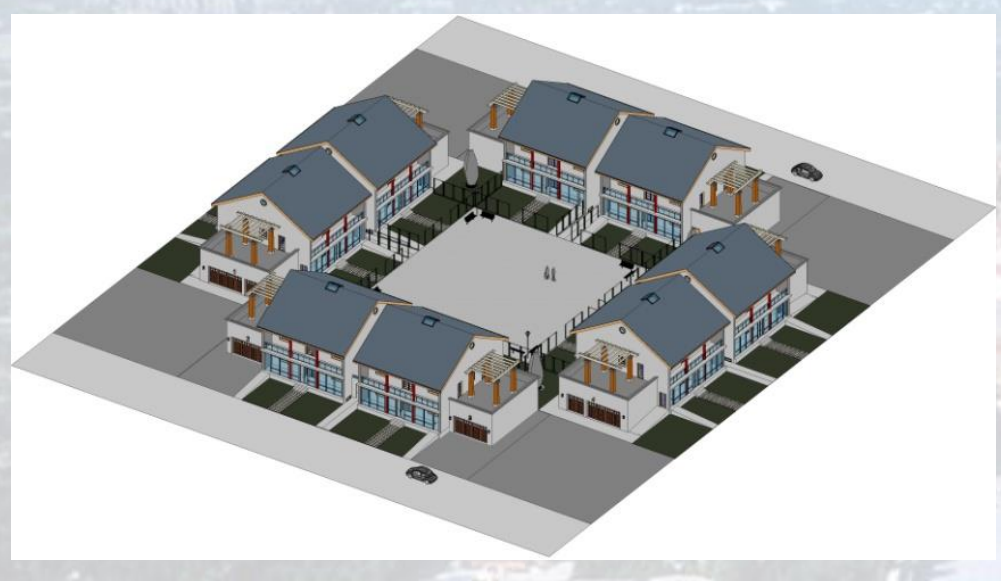

Scheme A of the proposed courtyard garden house compound housing 8 nuclear families. Design and model by Donia Zhang 2012-2014

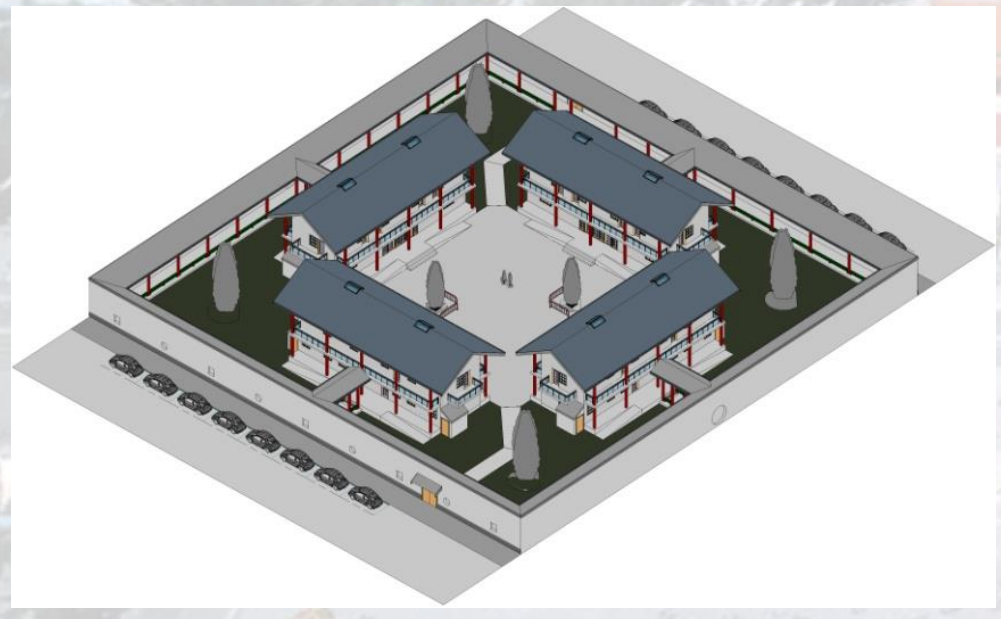

Scheme $\mathrm{C}$ of the proposed courtyard garden house compound housing 8 nuclear families. Design and model by Donia Zhang 2008-2013

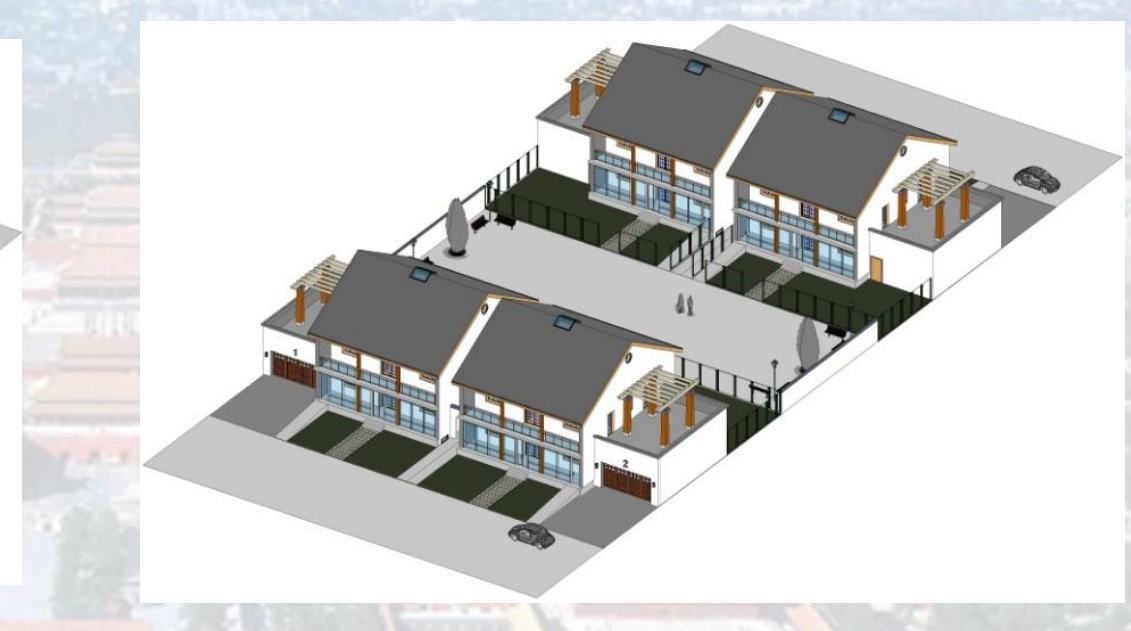

Scheme B of the proposed courtyard garden house compound housing 4 nuclear families. Design and model by Donia Zhang 2012-2014

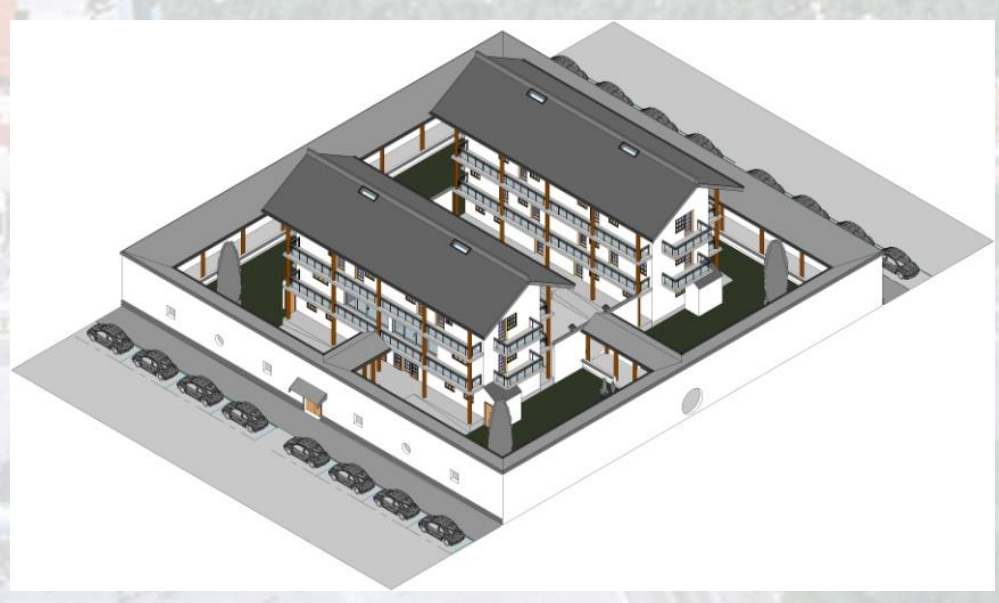

Scheme $D$ of the proposed courtyard garden house compound housing 4 nuclear families. Design and model by Donia Zhang 2008-2013 


\section{Proposed New Courtyard Garden Houses Scheme A}

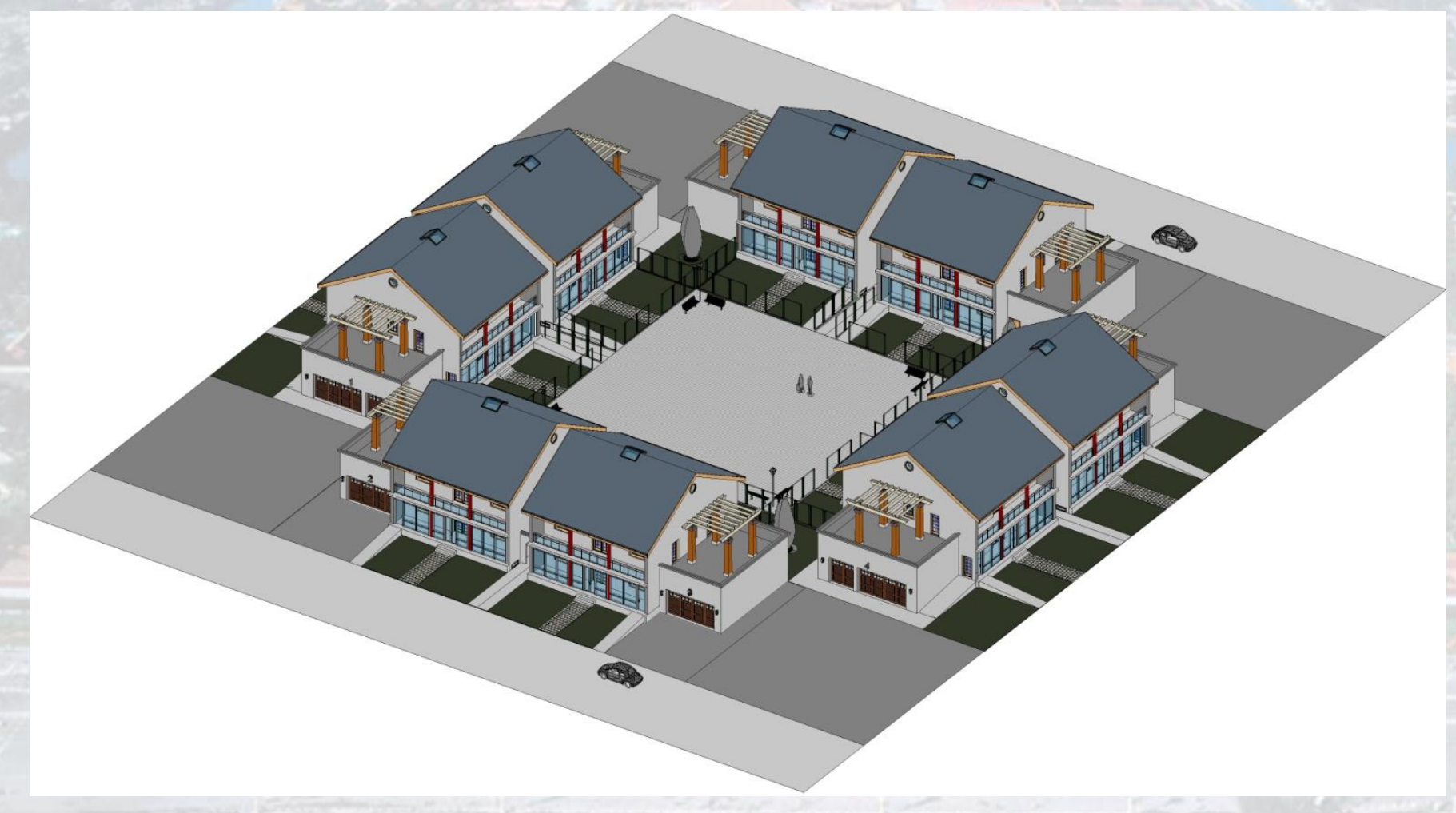

Proposed new courtyard garden house compound based on a system of $78 \mathrm{~m} \times 78 \mathrm{~m}$ standard block size, the communal courtyard is $26 \mathrm{~m} \times 26 \mathrm{~m}$ shared by eight nuclear families, with each household enjoying a private garden of $12 \mathrm{~m} \times 6 \mathrm{~m}$ at the front and the back. Each housing unit measures $10 \mathrm{~m} \times 12 \mathrm{~m}$ (total 240 sqm) with a semi-basement and $21 / 2$ storeys. Design and drawing by Donia Zhang 2012-2014 


\section{Proposed New Courtyard Garden Houses Scheme B}

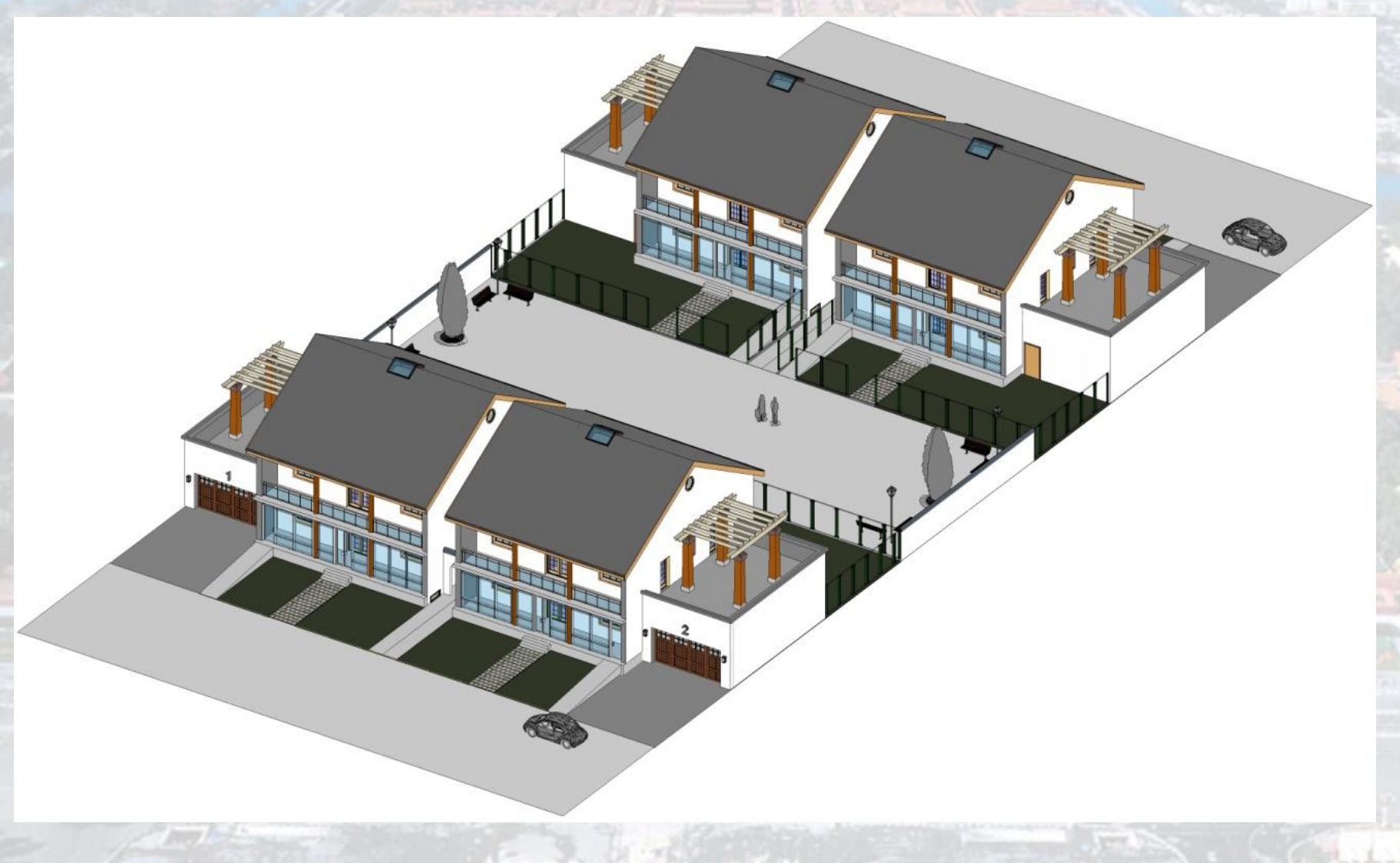

Model of the proposed new courtyard garden house compound based on a system of $40 \mathrm{~m} \times 66 \mathrm{~m}$ standard block size, the communal courtyard is $14 \mathrm{~m} \times 40 \mathrm{~m}$ shared by four nuclear families, with each household enjoying a private garden of $12 \mathrm{~m} \times 6 \mathrm{~m}$ at the front and the back. Each housing unit measures $10 \mathrm{~m} \times 12 \mathrm{~m}$ (total $240 \mathrm{sqm}$ ) with a semi-basement and 2 1/2 storeys. Design and drawing by Donia Zhang 2012-2014 


\section{Proposed New Courtyard Garden Houses Scheme C}

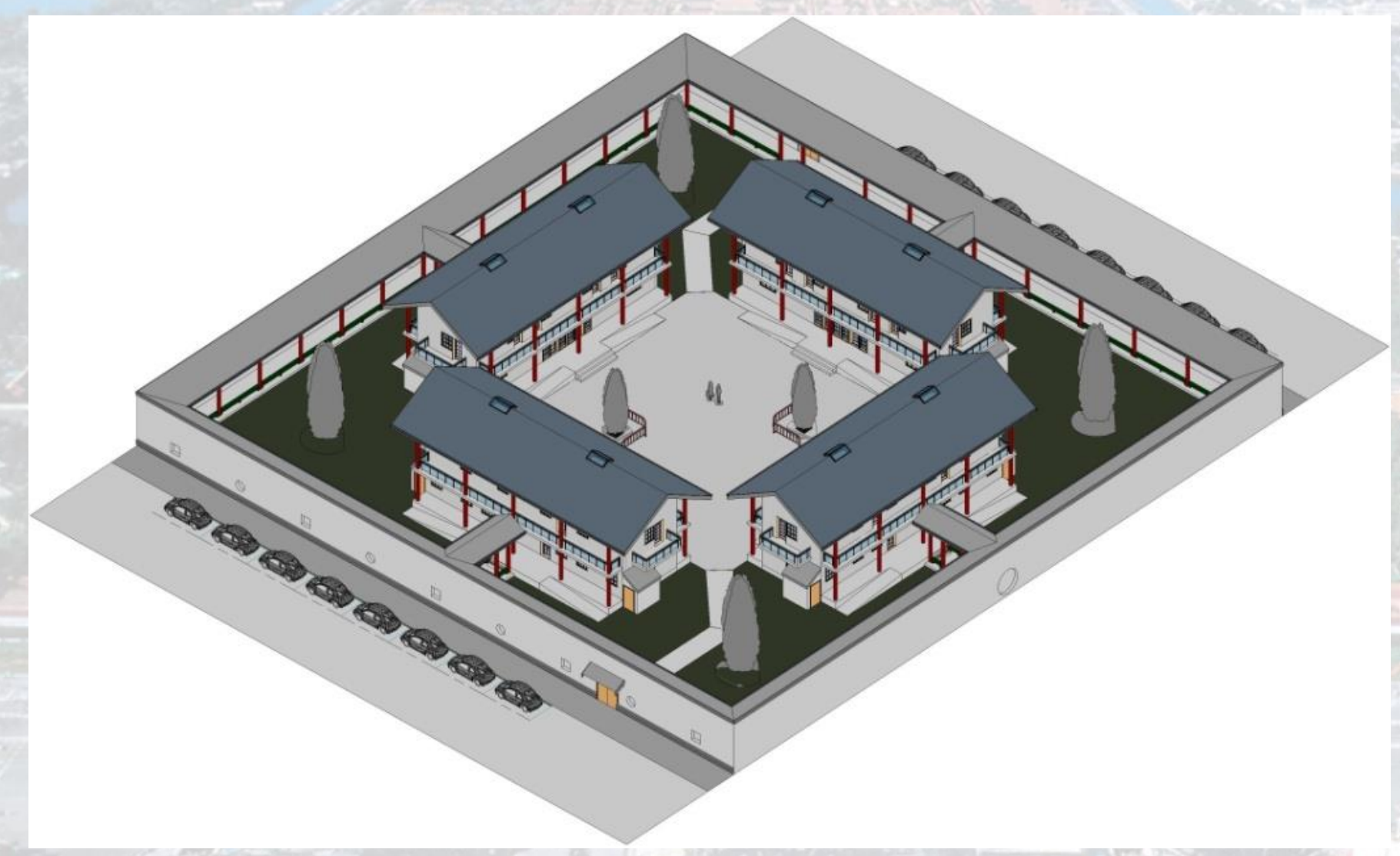

Model of the proposed Beijing new courtyard garden house compound based on a system of $60 \mathrm{~m} \times 60 \mathrm{~m}$ standard block size, the communal courtyard is $26 \mathrm{~m} \times 26 \mathrm{~m}$ shared by 8 nuclear families, and each household also enjoys a private garden at the back. Each housing unit measures $6 \mathrm{~m} \times 10 \mathrm{~m}$ (total $180 \mathrm{sqm}$ ) with a semi-basement and $21 / 2$ storeys. Design and drawing by Donia Zhang 2008-2013 


\section{Proposed New Courtyard Garden Houses Scheme D}

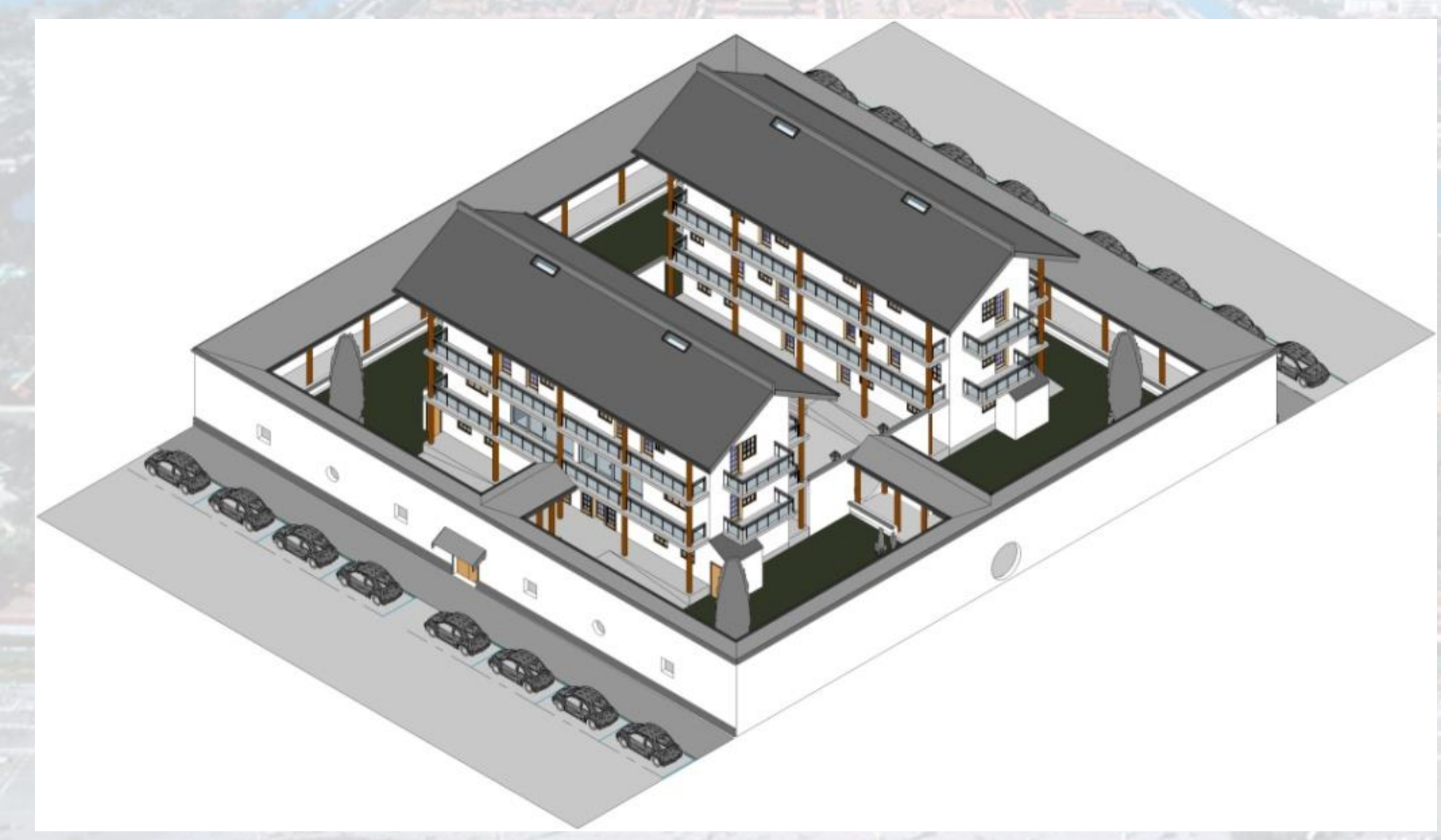

Model of the proposed Suzhou new courtyard garden house compound based on a system of $40 \mathrm{~m} \times 40 \mathrm{~m}$ standard block size, the communal courtyard is $12 \mathrm{~m} \times 20 \mathrm{~m}$ shared by 4 nuclear families, and each household also enjoys a private garden on the side. Each housing unit measures $6 \mathrm{~m} \times 10 \mathrm{~m}$ (total $180 \mathrm{sqm}$ ) with 3 storeys. Design and drawing by Donia Zhang 2008-2013 


\section{谢谢 \\ Thank you}

References:

Zhang, D. (2013). Courtyard Housing and Cultural Sustainability: Theory, Practice, and Product. Oxfordshire: Routledge.

Zhang, D. (2015). Courtyard Housing for Health and Happiness: Architectural Multiculturalism in North America. Oxfordshire: Routledge.
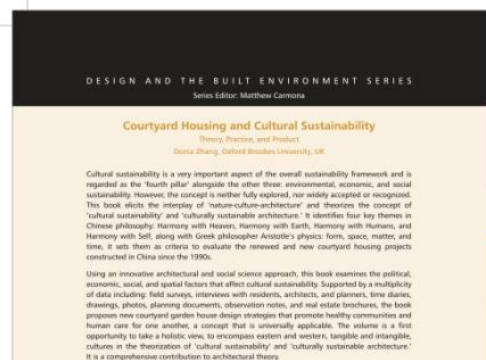

$\mathbb{R}$ Routledge

\section{R}

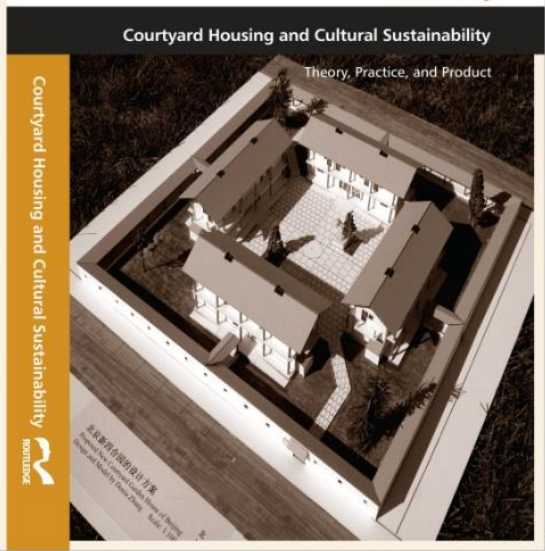

Courtyard Housing for Health and Happiness

Architectura

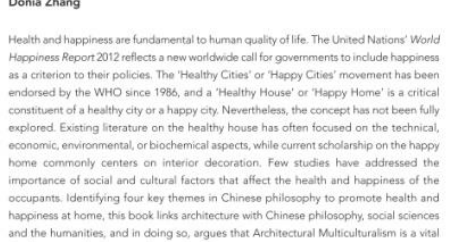

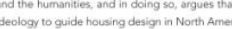

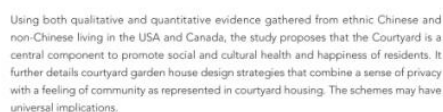

$\mathbf{R}_{\text {Routledge }}^{\text {Rour }}$

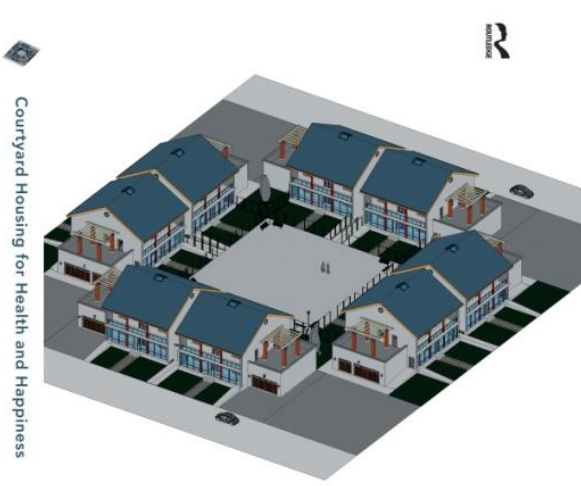

Courtyard Housing for Health and Happiness Architectural Multiculturalism in North America 